Article

\title{
A Study on Dynamic Patterns of Technology Convergence with IPC Co-Occurrence-Based Analysis: The Case of 3D Printing
}

\author{
Ying Tang ${ }^{1}$, Xuming Lou ${ }^{1}{ }^{1 *}$, Zifeng Chen ${ }^{1}$ and Chengjin Zhang ${ }^{2}$ \\ 1 School of Economics and Management, Xi'an University of Posts and Telecommunications, \\ Xi'an 710061, China; yanping@stu.xupt.edu.cn (Y.T.); chenzifeng@xupt.edu.cn (Z.C.) \\ 2 School of Modern Post, Xi'an University of Posts and Telecommunications, Xi'an 710061, China; \\ xike@stu.xupt.edtu.cn \\ * Correspondence: louxuming@xupt.edu.cn
}

Received: 30 January 2020; Accepted: 23 March 2020; Published: 27 March 2020

\begin{abstract}
Technology convergence has become a typical characteristic of innovation, which affects the evolution of industrial structures and the core competitiveness of organizations. However, the existing research has mainly focused on the development of core areas of convergence, ignoring the potential breakthroughs that emerging peripheral convergence may bring. Therefore, this research put forward a comprehensive methodology based on IPC (International Patent Classification) co-occurrence analysis to study the dynamic patterns of technology convergence from the perspectives of reinforcing convergence and novel convergence. For the former, convergence trends in each period were explored by using association rules, and the convergence degree was measured based on the number of patents containing different IPC codes. Then, the corresponding core technical fields were identified by using information entropy. For the latter, a community detection algorithm based on IPC co-occurrence network was adopted to investigate the convergence trend by period, and important technology fields were identified by the centrality indicators. The methodology proposed in this study is beneficial for firms to seize technological opportunities in technology convergence.
\end{abstract}

Keywords: technology convergence; association rules; information entropy; network analysis

\section{Introduction}

In recent decades, with the intensification of market competition and increasing changeability of consumer demand, organizations are confronting more challenges to innovate faster, at a lower cost, and with more competition. Adner [1] pointed out that when the performance of a technology begins to meet the needs of consumers in multiple market areas, the differences between these areas gradually became blurred, resulting in a fundamental change in the competitive position of enterprises. As a significant feature of current innovation trends, technology convergence has brought new opportunities for organizations to deal with challenges and obtain competitive advantages [2-5]. Some research has illustrated that innovation brought by technology convergence can not only improve technical functions and enhance product competitiveness, but it can also result in disruptive innovation and create new industries [6-8]. Therefore, identifying and anticipating the patterns of technology convergence are beneficial for firms to optimize resource allocation and seize innovation opportunities for further progress or even leapfrog development.

Some research on technology convergence have been carried out from a static perspective to identify the key fields where convergence has occurred $[9,10]$, or they discuss the typical convergence patterns and possible future convergence in target fields in periods according to the characteristics of technology development [11-13]. Although valuable contributions to the development of convergence 
innovation have been made, especially in the fields of information and communication technologies, biotechnology and nanotechnology $[3,8,14,15]$, etc., the efforts have been mainly focused on the central area of convergence, ignoring the potential breakthroughs of the burgeoning borderline convergence technology. Alexander et al. [16] noted that the inflow of heterogeneous knowledge and resources is conducive to improving breakthrough innovation capacity, which enables companies with fewer resources to successfully challenge existing businesses [17]. Su et al. [18] observed that disruptive technologies are not popular at the beginning of their development, but they eventually evolve into disruptive technologies that dominate the market with the continuous improvement of technical performance. Given that technology convergence is an important channel to generate disruptive innovation [6], this study conducted a comprehensive analysis of technology convergence both from its center and periphery to overcome the limitations of previous research and help organizations optimize resource allocation and achieve sustainable development.

In this study, we adopted Caviggioli's [9] definition of technology convergence based on the co-occurrence of 4-digit IPC codes (IPC4), that the first occurrence of a combination of two IPC subclasses is considered as the birth of a converted technology. Technology convergence was divided into two categories, i.e., reinforcing technology convergence and novel technology convergence, according to this definition [19]. Reinforcing technology convergence refers to the continuity and repetitive IPC4 combinations that emerged already before, while novel technology convergence means the IPC4 co-occurrence for the very first time. Exploring the already existing IPC4 combinations is beneficial to figure out the deepening process of convergence between technical fields, while detecting the first appeared IPC4 combinations can better track the extension of convergence into other heterogeneous fields. We utilized association rules to identify the core components of technology convergence and investigate the dominant convergence patterns in each period. Information entropy was applied to predict the recent trends of technology convergence in the target field. Additionally, IPC4 co-occurrence networks were constructed for novel technology convergence, and the horizontal extension of convergence was analyzed by combining cluster analysis and the development history of $3 \mathrm{D}$ printing. Moreover, important technical components of new convergence that have the potential to result in disruptive innovations were identified according to particular network indicators. Understanding comprehensively about the development of technology convergence can contribute to the management of technology innovation.

The structure of this study is as follows: the "Research backgrounds" section reviews previous theoretical research on technology convergence, describes major empirical research based on patents and discusses the mainstream methods used in this field. The "Methodology" section proposes a methodology for the comprehensive identification of two kinds of technology convergence patterns and future trends. Then, the proposed methodology is verified by 3D printing patents in the "Empirical research" section. Finally, the "Conclusions" section summarizes the research results and limitations.

\section{Literature Review}

\subsection{Theoretical Researches on Technology Convergence}

Technology convergence research originated in the 1960s when Rosenberg observed that some industries have large overlaps in technologies and processes, in spite of the different final products, which means that technology convergence is closely related to industrial development [20]. However, it was not until the 1980s that technology convergence attracted wide attention from scholars who gave variable connotative definitions for it [21]. Schnaars et al. [7] argued that technology convergence is a combination of two or more distinct technologies that can create new products or even new industries. Choi et al. [22] explained that technology convergence refers to transforming technologies from different application areas into new and shared technical unities. Among these studies, the most widely accepted definition is that technology convergence (or fusion) is triggered by the blurring or 
fading of boundaries between at least two hitherto disjoint areas [21,23], and it is consistent with others' description about convergence [24,25].

Furthermore, Curran and Leker [23] distinguished convergence and fusion, which have different meanings. They noted that convergence is such a process that objects move or stretch further from their prior and discrete spots to a new and common place, while fusion happens when objects begin to merge with each other in the very same place of at least one technology, which is followed by several researchers $[8,21,26]$. Other researchers have also tried to classify convergence from different perspectives. Stieglitz [27] stated from an industry perspective that the technology convergence involved in its development process can be divided into technology substitution and technology integration. Kim and Lee [28] categorized technology convergence into interrelated convergence and intermediated convergence, where all the technologies in the former are closely related to each other and extensively exchange knowledge, while the latter implies that there is a particular technology that mediates the convergence of technologies.

For the important role that technology convergence plays in industrial and economic development, it is crucial to know what drives technology convergence. Researchers noticed that standardization, as a selection process, promotes technology convergence, and this is structurally positively correlated $[29,30]$. Other studies observed network structure has an influence on technology convergence. For example, Jeong and Lee [31] found that improved institutional networks and new models of funding and evaluation criteria can serve as effective policies or management tools to facilitate technology convergence. Feng and Zeng [19] utilized Chinese automobile industry patents and standard data to analyze the complex and heterogeneous relationships among the embeddedness of collaborative R\&D (Research and Development) network structure, technical standard concentration and technology convergence. The empirical results show that the different structural embeddedness of the R\&D network has varied effects on technical standard concentration and can be both detrimental and beneficial. Structural embeddedness of R\&D networks stimulates technology convergence directly, but it has heterogeneous indirect effects via technical standard concentration.

The existing research mainly focused on the core scope of convergence and paid little attention to the breakthrough progress that may be brought by the newly emerging convergence, which is generally on the periphery and rarely noticed. In this study, we explored the development patterns of technology convergence from vertical deepening and horizontal extension dimensions, and we anticipate the important converging fields in the future.

\subsection{Empirical Research of Technology Convergence Based on Patents}

Multiple data sources have been used to study technology convergence, such as scientific literature [32], newspapers [26], Wikipedia hyperlinks [14] and some open national R\&D and knowledge service information $[31,33]$, while patent data has been used most for its reliable and novel information and knowledge of technological innovation [34,35]. Two significant features of patent data make it an effective source to study technology convergence: its clear hierarchical structures of IPC codes and citation information representing knowledge flow [9].

Firstly, different levels of technology fields can be mapped according to the hierarchy of IPC codes, which support the measurement of technology distance at different levels. Moreover, a patent may have multiple IPC codes, and their co-occurrence information can be used to measure the merging status between distinct fields. Some scholars utilized IPC4 codes to study technology convergence because it can better match technology classification of ISI-OST-INPI [36] or SIC (Standard Industrial Classification), whose classification can be used as a starting point to analyze particular topics at a lower level of aggregation. For example, Choi et al. [22] mapped patents into technology categories according to the IPC co-occurrence analysis, and then they empirically measured the convergence degree of technologies and estimated its diffusion trend in general. Song et al. [8] predicted the emerging technology convergence based on the knowledge flow between main classification and secondary classification of patent IPC4 codes with a corresponding indicator to measure the converging 
technologies. Several other studies have also adopted this level of IPC classification $[9,29,31]$. In addition, there are some articles devoting to the study of convergence in more detailed fields, which adopted seven-digit or eight-digit IPC codes to carry out the co-occurrence analysis [12,15].

Secondly, patent citations can track the flow of knowledge between technology fields, which depends on the cumulative and irreversible view of technological progress [37], thus patent citation analysis is another main approach to study the convergence of technologies. Among the relevant studies, the work of Kim et al. [30] is representative, as they explored the technology evolution trajectory with the combination of technology convergence, which can better reflect the performance of convergence in technology progress. Other researchers identified key areas and forecasted the trend of technology convergence in target areas accordingly. Kim et al. [11] investigated the evolution of the core technology convergence over time and the corresponding models based on closeness centrality and betweenness centrality of the citation network. Kim and Lee [28] studied the convergence of information technology and biotechnology based on the citation matrix and a DSM (dependency structure matrix) sequencing algorithm. Park and Yoon [38] suggested technological opportunities for convergence by predicting potential technological knowledge flows between biotechnology and information technology based on their mutual patent citations, enabling R\&D decision makers to plan new R\&D projects on technology convergence.

Additionally, some studies combined IPC codes with patent citations or used one of them with other types of data for technology convergence analysis. Combined with patent citation analysis and IPC co-occurrence information, it can analyze the performance of knowledge flow, as well as the intensity, rate and coverage of convergence among distinct fields simultaneously [3,4]. Furthermore, a few studies chose to integrate other specific data to study certain objects such as specific companies or industries. Duysters and Hagedoorn [39] used patent data of information and communication technologies and strategic technology alliances data to investigate the impact of technology convergence on the core competitiveness of information technology companies. Curran and Leker [23] exploited the convergence of plant sterols and information and communication technologies, respectively, based on IPC co-occurrence and scientific literature. Kim and Lee [28] proposed a methodology to forecast multi-technology convergence based on a patent-citation analysis, a dependency structure matrix, and a neural network analysis. Du et al. [40] conducted a study on the knowledge translation and convergence in a complete chain of pharmaceutical innovation by designing a product-patent-paper-funding backward tracking model. Since IPC hierarchy could be mapped to technical categories properly, this study chose the IPC4 of patent data to investigate the dynamic evolution of converging patterns and, furthermore, anticipates the core components of future convergence.

\subsection{Research Methods on Technology Convergence}

The existing research on technology convergence can be divided into three categories according to their research themes: identification, measurement and anticipation. In identification research, association rules, information entropy, betweenness centrality and other network indicators are frequently used to detect key areas, core components or evolution models of technology convergence. Kim et al. [11] proposed a novel methodology to study the co-evolution pattern in technology convergence by analyzing the trajectories of closeness centrality value and betweenness centrality value in citation networks. Lee et al. [12] utilized association rules to identify important convergence patterns in different periods based on the entire triadic patents. Han and Sohn [15] applied entropy, binding force and association rules to essential patents in order to reveal technical areas with different importance.

Among the early works of convergence measurement research, some scholars used the input-output method $[41,42]$ or patent coefficient methods $[43,44]$ to measure the degree of technology convergence, which could not reflect the integration of different technological trajectories. Thus, some other researchers have introduced several indicators to make up for this deficiency. Choi et al. [22] measured the technology convergence degree by the percentage of convergence patents. Song et al. [8] proposed relative convergence based on inter-patent knowledge flow, aiming to measure the ratio 
between the intensity of converging technology patterns and the sum of existing linkages in the data set. Several multidimensional indicators have also been developed such as the breadth and depth of technology convergence, which are based on biodiversity indicators [45], citation rate, cosine similarity and Jaccard index related to evaluate the technology relatedness [13,32].

As an important channel to generate innovation, accurate anticipation of technology convergence can help governments and organizations to optimize resource allocation and improve innovation efficiency. Several studies have been carried out with link prediction and neural network analysis. For example, Lee et al. [12] applied link prediction to forecast possible convergence in the next stage, which was conducted on frequent pattern mining. Kim and Lee [28] developed a future citation matrix by neural network analysis to predict convergence between information technology and biotechnology. Kim et al. [13] analyzed important technologies that may be merged with 3D printing technology in the future by link prediction. Although forecasting where technology convergence is likely to go can bring competitive advantages, the results need to be treated with caution because the convergence usually takes decades longer than expected and often does not resemble what was originally anticipated [7]. Therefore, this paper investigated the core components and trends of technology convergence by combining association rules and information entropy, and it proposed a suitable indicator to measure the technology convergence degree. For the periphery of emerging technology convergence, it used network indicators to carry out related research.

\section{Methodology}

Figure 1 shows the research framework proposed in this study. It includes five steps: selecting the target technology field and database, data collection and preprocessing, analyzing technology convergence patterns, measuring technology convergence and identifying key technology convergence components. The main work of the first two steps is to select the target technology field with converging characteristics and appropriate database, and then to determine the corresponding search strategy to obtain an effective patent data set and select a relevant attribute set for preprocessing. Subsequently, the research is carried out from the perspectives of reinforcing technology convergence and novel technology convergence. For the former, core convergence patterns are mined and analyzed by association rules, and their convergence degrees are measured by the indicator technology convergence degree, and then the information entropy is applied to identify key convergence components. For the latter, important novel convergence patterns are analyzed by cluster analysis, and the corresponding key convergence components are identified according to betweenness centrality and bridging centrality. Relevant details are presented in Sections 3.1 and 3.2.

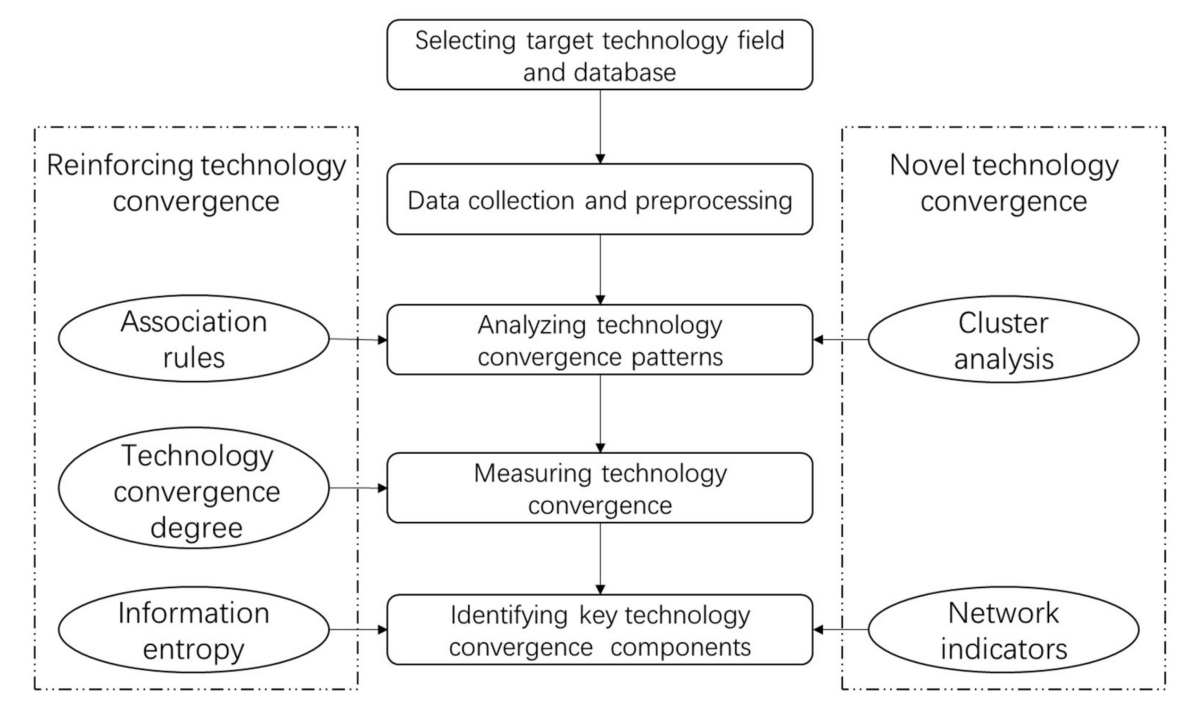

Figure 1. General framework for dynamic pattern study of technology convergence. 


\subsection{Reinforcing Technology Convergence}

\subsubsection{Convergence Patterns Analysis Based on Association Rules}

In this study, an association rule was used to mine significant convergence patterns in IPC co-occurrence analyses of patents. As an important branch of data mining, association rule is purposed to initially mine the implicit connections behind basket data, which has been used widely, and there are basic indicators such as support and confidence to measure the quality of rules [46]. The Apriori algorithm and FP-Growth (Frequent Pattern-Growth) algorithm are commonly used, in which the former mines frequent item-sets by limiting the generation of candidate items [47], while the latter mines frequent item-sets through pattern growth [48]. For large-scale data, the FP-Growth algorithm is more efficient since the Apriori algorithm needs to scan the database multiple times, while the FP-Growth algorithm only scans twice in the process.

The appropriate association rules were selected to study reinforcing technology convergence patterns according to the data collected. We obtained frequent item-sets of length 2 and determined the minimum support and confidence thresholds to gain meaningful converging relations. Here, the support index for IPC $i$ and IPC $j$ refers to the probability that IPC $i$ and IPC $j$ appear in the same patent simultaneously, while the confidence indicates the possibility of including IPC $j$ in patents containing IPC $i$.

\subsubsection{Indicator for Reinforcing Technology Convergence Degree}

The degree of technology convergence reflects the integration of different technology trajectories [29, 30], and effective measurement contributes to take in the relevant development status. Choi et al. [22] proposed that the technology convergence degree equals the number of convergence patents divided by the total number of all patents. Chen et al. [10] explored the convergence breadth and depth, among which breadth represents the diversity of technical topics included in convergence, while depth indicates the convergence frequency in a given technical topic. Considering the precondition for selecting 2 frequent item-sets in this study, and referring to the previous research on the degree of technology convergence, we developed the indicator $\mathrm{Con}_{\text {deg }}$ to measure the convergence of strong association rules. The definition of this indicator is shown as Equation (1).

$$
\mathrm{Con}_{\text {deg }}=\frac{\text { The number of patents containing IPC } i \text { and IPC } j}{\text { The number of patents containing IPC } i \text { or IPC } j}
$$

\subsubsection{Identification of Key Converging Components Based on Information Entropy}

Information entropy is an important indicator that can be used to measure the diversity of technology convergence [15,29]. After investigating the significant convergence patterns by association rule analysis, the core technology components that interact frequently with others within them can be further identified by the information entropy. This was used to evaluate the interaction activeness of each IPC4 with other technical fields for the reinforcing technology convergence. The expression of this indicator is shown as Equation (2).

$$
E_{i}=-\sum_{j} p_{j / i} \log _{2} p_{j / i}
$$

where $E_{i}$ indicates the entropy of component $i, j$ represents the other technical fields associated with $i$ and $p_{j / i}$ denotes the probability that patents include $j$ in the case of containing $i$. The higher the entropy is, the more important the component is for the convergence patterns. 


\subsection{Novel Technology Convergence}

\subsubsection{IPC Co-Occurrence-Based Community Detection}

In view of the small scale and weak signal of novel technology convergence in its forming stage, a community detection method based on IPC co-occurrence networks was adopted to reflect the convergence status and investigate relevant patterns. However, the convergence degree was not measured here for its sparsity, in contrast with reinforcing technology convergence. Community structure is one of the key features of graphs $[49,50]$ and it can be divided according to the local density. The connections within the community are relatively tight, while the connections between communities are relatively sparse. Newman [51] proposed the concept of modularity, which is used to measure the structural strength of network communities. High modularity means strong structural strength of the network community, and it also indicates that the network has significant community partition. In general, modularity greater than 0.3 means that the network community is well divided. In this study, the fast-unfolding algorithm [52] has been applied to find the optimal modularity partition. The IPC codes within the same community were considered more likely to merge, otherwise the convergence trend was not significant. The calculation of modularity is shown as Equation (3).

$$
Q=\frac{1}{2 m} \sum_{i, j}\left[A_{i, j}-\frac{k_{i} k_{j}}{2 m}\right] \delta\left(c_{i}, c_{j}\right)
$$

where $m=\frac{1}{2} \sum_{i, j} A_{i, j}$ represents all the weights in the network, $A_{i, j}$ is the weight of the edge between component $i$ and $j, k_{i}=\sum_{j} A_{i, j}$ denotes the sum of the weights of the edges connected to $i, c_{i}$ is the community to which $i$ is assigned, and $\delta\left(c_{i}, c_{j}\right)$ is used to determine whether $i$ and $j$ are divided in the same community. If so, it returns 1 ; otherwise, it returns 0.

\subsubsection{Identification of Key Converging Components Based on Network Indicators}

Betweenness centrality is one of the famous indexes to measure the global importance of a node, which is calculated by dividing the number of shortest paths passing through the particular node by the total number of shortest paths [53]. Nodes with high betweenness centrality have more opportunities to control the flow of resources; therefore, it is used to identify key components of technology convergence $[10,11,30]$. Accordingly, this study also utilized this index to achieve the same goal, and its definition is shown as Equation (4).

$$
C_{B}(v)=\sum_{\substack{i \neq v \neq j \\ i, v, j \in V}} \frac{\sigma_{i j}(v)}{\sigma_{i j}}
$$

where $C_{B}(v)$ is the betweenness centrality of component $v, V$ denotes the set of components, $\sigma_{i j}$ is the number of shortest paths from $i$ to $j$, and $\sigma_{i j}(v)$ represents the number of shortest paths from $i$ to $j$ passing through $v$. The higher the betweenness centrality, more information travel through $v$.

However, considering that the shortest path between pairs of nodes is likely to pass through the central nodes [54], other important nodes in the network topology may be ignored when just using betweenness centrality exclusively. Ramanathan et al. [55] considered that there should be bridging nodes between modules connecting dense cliques in a scale-free network, which should be an attractive and important basic component in the network. In order to identify the nodes that are critical to facilitate knowledge flow and interactions between modules, they proposed bridging centrality. For the emergence of novel technology convergence, the peripheral region focusing on convergence extension is as important as the core region. Therefore, we further identify the corresponding technology 
convergence components with bridging centrality. The relevant calculations are shown as Equations (5) and (6).

$$
\begin{gathered}
B C(v)=\frac{d(v)^{-1}}{\sum_{i \in N(v)} \frac{1}{d(i)}} \\
C_{B r}(v)=B C(v) \times C_{B}(v)
\end{gathered}
$$

In the first equation above, $B C(v)$ is the bridging coefficient of $v, d(v)$ is the degree of $v$, and $N(v)$ is the set of neighbors of $v$. The bridging coefficient assesses the local bridging characteristics in the neighborhood [55]. In the second equation above, $C_{B r}(v)$ is the bridging centrality of $v$, which also indicates that it is the product of bridging coefficient and betweenness centrality

\section{Empirical Analysis}

\subsection{Selection of the Target Technology Field}

In this study, 3D printing technology was selected for three reasons. Firstly, as an emerging integrated manufacturing technology, 3D printing combined with cutting-edge knowledge in digital modeling, materials science, chemistry and electromechanical control, has realized the integration of design and manufacture, which can meet the needs of mass customization [56]. Secondly, 3D printing technology has characteristics of general-purpose technologies, whose application fields are highly dispersed, and it shows great scope of improvement as in its early state of maturity [57]. Finally, 3D printing has been highly valued by both developed countries and emerging economies, and it has been considered to be one of the most noteworthy technological development trends in the world [58]. However, few studies have discussed the development of 3D printing from the perspective of technology convergence. By referring to the works of Liu et al. [59] and Kim et al. [13], we integrated related subject terms with keywords of technology process to determine the search strategy and chose Derwent Innovations Index with comprehensive information to obtain patent data. Table 1 lists the related terms and technology processes of 3D printing.

Table 1. Keywords of 3D printing search strategy.

\begin{tabular}{cc}
\hline Subject Terms & Subordinate Technology Processes \\
\hline & Fused deposition modeling (FDM); Electron-beam freeform \\
fabrication (EBF) \\
3D printing; Additive manufacturing & Selective heat sintering (SHS); Selective laser sintering \\
3D printer; Additive fabrication & (SLS); Powder bed and inkjet head (PP) \\
Three-dimensional printing & Direct metal laser sintering (DMLS); Melted and extrusion \\
& modeling (MEM); Stereolithography (SLA) \\
Layer manufacturing & Laminated object manufacturing (LOM); Fused filament \\
& fabrication (FFF); Digital light processing (DLP) \\
\hline
\end{tabular}

\subsection{The overall Distribution of $3 D$ Printing Patents}

3D printing-related patents from 1976-2018 were retrieved from Derwent Innovations Index according to the determined search strategy, and a total of 34,249 patents were retrieved in March 2019. The retrieval results included both applications and granted patents, as there is a significant application-grant lag, which will make it difficult to keep up with the latest development of emerging technologies using granted patents alone. Hall et al. noted that, whenever possible, the application date should be used as the relevant time placer for patents, and we followed this recommendation [34]. Figure 2 shows the number of convergence patents (a patent containing two or more IPC 4 codes) and non-convergence patents (a patent containing only one IPC4 code) in the 3D printing field each year. It can be seen that with the rapid growth of patents, the convergence patents maintained synchronous growth and split equally with the non-convergence patents, indicating that cross-border development has been a long-term feature for 3D printing technology. Due to the truncation of granted patent 
data sets [34], the number of patents in the past two years has not been fully obtained. Obviously, the development of 3D printing technology was relatively slow in the early stage, and there has been a slow growth since 2002; the growth rate has increased significantly from 2012. In combination with the development history of 3D printing, we divided the collected patents into four periods for technology convergence research. Firstly, 1976-2006 is the first stage, in a state of steady development. Secondly, the expiration of the SLA (Stereo Lithography Apparatus) patent in 2007 caused a development wave of 3D printing, and in 2012, the US proposed a plan to revitalize the manufacturing industry, pushing the wave of 3D printing to its peak, hence the second research stage was from 2007-2012. Then, according to Wohlers Report 2018 [60], after the growth rate of the 3D printing market size reached its highest in 2012, it slowed down in 2013-2015 but remained at the medium-high speed growth stage of 30\%, followed by the growth rate further reducing and presenting certain fluctuations in 2016-2018, thus representing the third and fourth stages, respectively.

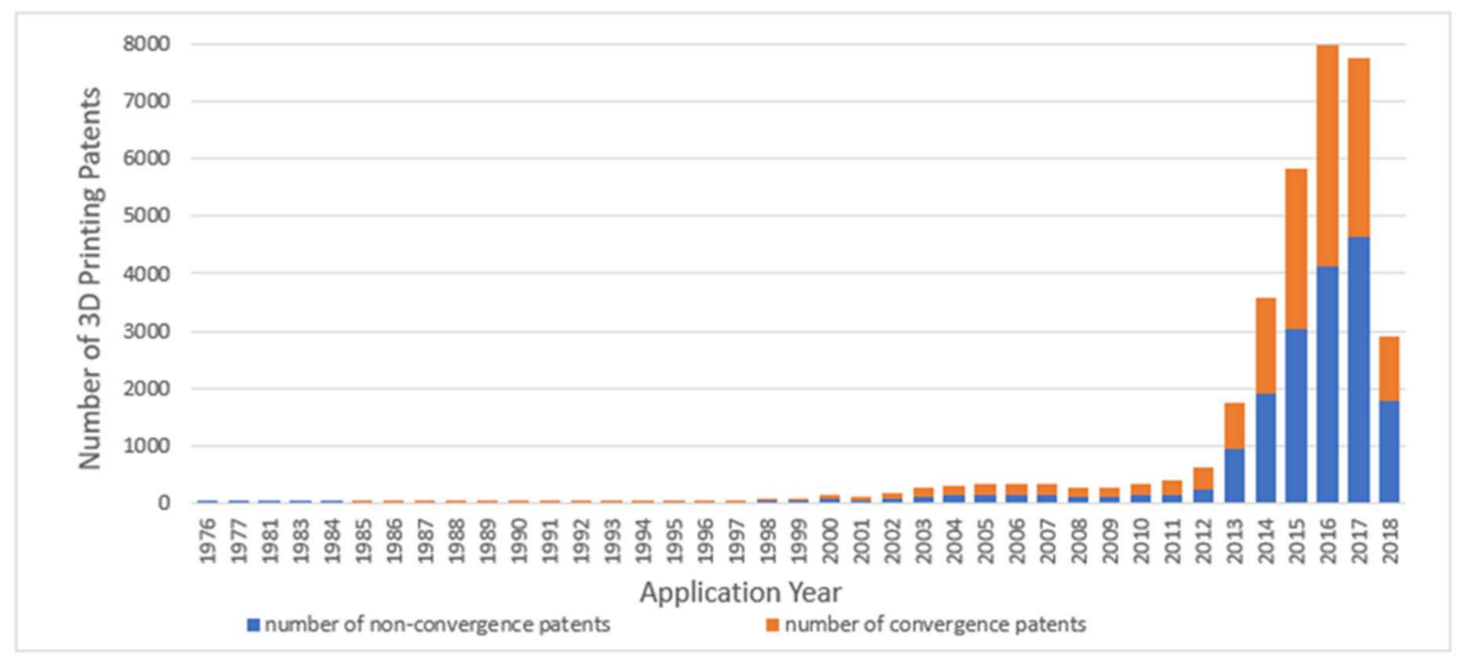

Figure 2. Number of patents in 3D printing technology.

The total number of patents in each period and the corresponding convergence patents are shown in Table 2. It can be found that with the rapid increase of 3D printing patents in recent years, convergence patents have increased at an even faster rate. In the most recent period, the number of convergence patents has reached 15,331 , accounting for $82.19 \%$ of the total number of patent applications in this stage.

Table 2. Patent application in each period.

\begin{tabular}{cccc}
\hline Period & Number of Patents & Convergence Patents & Percent \\
\hline $1976-2006$ & 2144 & 1419 & $66.18 \%$ \\
$2007-2012$ & 2260 & 1583 & $70.04 \%$ \\
$2013-2015$ & 11,193 & 7783 & $69.53 \%$ \\
$2016-2018$ & 18,653 & 15,331 & $82.19 \%$ \\
\hline
\end{tabular}

To explore the technology distribution of the patents, the WIPO (World Intellectual Property Organization) Concordance Table was used, which has mapped the IPC4 codes into 5 technology sectors and 35 technology fields [36]. Technology distribution has been studied at sector and field levels separately. At the technology sector level, as shown in Table 3, 83.47\% and $63.07 \%$ of the convergence patents have at least one IPC4 belonging to mechanical engineering and chemistry areas, respectively. In terms of intra-area convergence, the proportions of convergence patents that happened within the same areas were $2.29 \%, 0.34 \%, 1.85 \%$ and $5.97 \%$ for electrical engineering, instruments, chemistry and mechanical engineering, separately. However, most of the convergence patents happened in 
inter-different areas: $57.33 \%$ of them involved at least one mechanical engineering IPC4 and one chemistry IPC4. This means that over half of 3D printing technology convergence happened between mechanical engineering and chemistry, far more than other types. There could be two possible reasons for this. On the one hand, these two technology sectors contain the main 3D printing techniques (e.g., shaping or joining of plastics and additive manufacturing) and applied materials (e.g., organic macromolecular compounds and ceramics) respectively, and on the other hand, it is related closely with the important applications of 3D printing technology in automobile, industrial design, healthcare and so forth. The following most remarkable convergence happened among mechanical engineering, instruments and electrical engineering. Table 3 confirms the convergence universality, diversity and expanding elasticity.

Table 3. Technology distribution of convergence patents based on the WIPO Concordance Table.

\begin{tabular}{|c|c|c|c|c|c|c|c|}
\hline \multicolumn{2}{|c|}{$\begin{array}{l}\text { WIPO Concordance } \\
\text { Table Areas }\end{array}$} & \multirow{2}{*}{$\begin{array}{c}\begin{array}{c}\text { Convergence } \% \\
\text { Involving the } \\
\text { Total Area }\end{array} \\
23.55 \%\end{array}$} & \multirow{2}{*}{$\begin{array}{c}\begin{array}{c}\text { Convergence\% } \\
\text { with 1(\%) }\end{array} \\
2.29 \%\end{array}$} & \multirow[t]{2}{*}{$\begin{array}{l}\text { Convergence } \% \\
\text { with } 2(\%)\end{array}$} & \multirow[t]{2}{*}{$\begin{array}{c}\text { Convergence } \% \\
\text { with } 3(\%)\end{array}$} & \multirow[t]{2}{*}{$\begin{array}{l}\text { Convergence } \% \\
\text { with } 4(\%)\end{array}$} & \multirow[t]{2}{*}{$\begin{array}{l}\text { Convergence } \% \\
\text { with } 5(\%)\end{array}$} \\
\hline 1 & $\begin{array}{c}\text { Electrical } \\
\text { engineering }\end{array}$ & & & & & & \\
\hline 2 & Instruments & $27.73 \%$ & $11.87 \%$ & $0.34 \%$ & & & \\
\hline 3 & Chemistry & $63.07 \%$ & $4.29 \%$ & $7.73 \%$ & $1.85 \%$ & & \\
\hline 4 & $\begin{array}{l}\text { Mechanical } \\
\text { engineering }\end{array}$ & $83.47 \%$ & $12.17 \%$ & $17.03 \%$ & $57.33 \%$ & $5.97 \%$ & \\
\hline 5 & Other fields & $5.20 \%$ & $1.12 \%$ & $0.98 \%$ & $1.50 \%$ & $3.91 \%$ & $0.07 \%$ \\
\hline
\end{tabular}

At a more elaborate level of technology, the top four fields with the highest number of 3D printing patents, i.e., other special machines, materials metallurgy, macromolecular chemistry polymers and medical technology, were listed to describe the trend of convergence in each period, as shown in Figure 3. The number of 3D printing patents and convergence in the other special machines field was much more than the others, and its proportion of convergence has increased up to $97.23 \%$ in the latest period. It mainly results from the wide application of 3D printing at the industrial level, for example, making some metal components with complex shapes and diverse structures. Materials metallurgy and macromolecular chemistry polymers both have increased rapidly and had convergence ratios higher than the average in period four. The medical technology field had the fourth highest 3D printing patents, while the corresponding convergence rate was much lower than the other three and lower than the average in period four. Nevertheless, 3D printing technology involving medical or veterinary science is still primarily embodied by convergence technology.

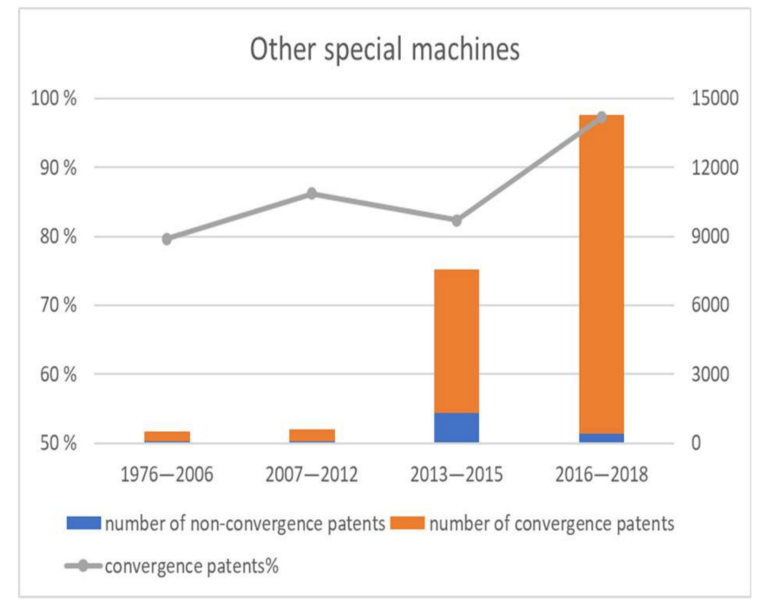

(a)

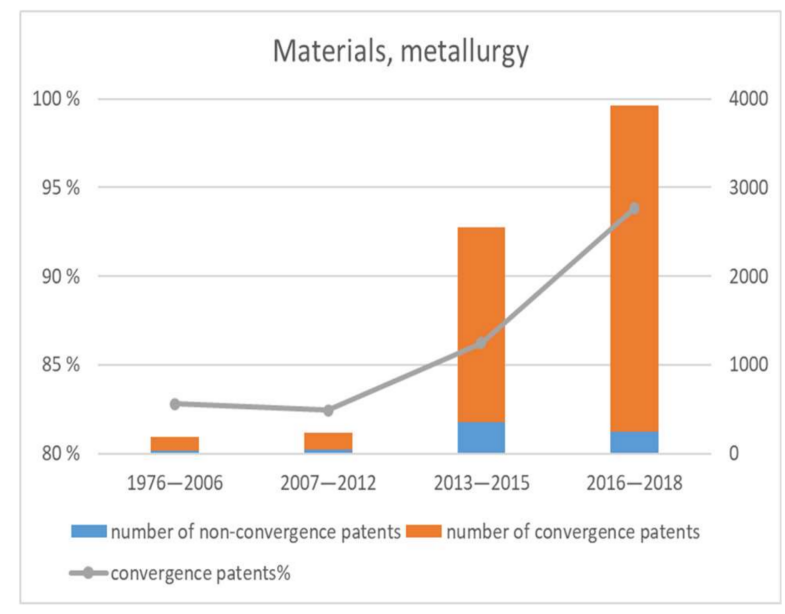

(b)

Figure 3. Cont. 


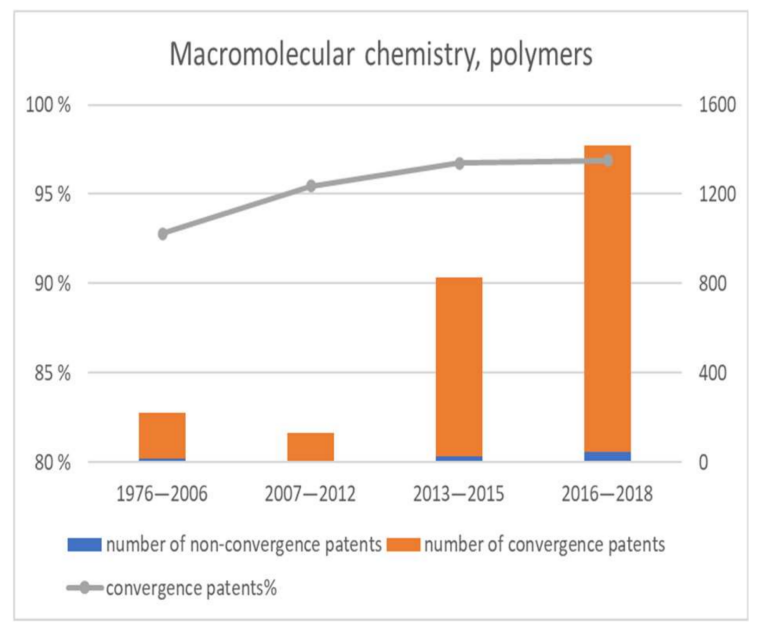

(c)

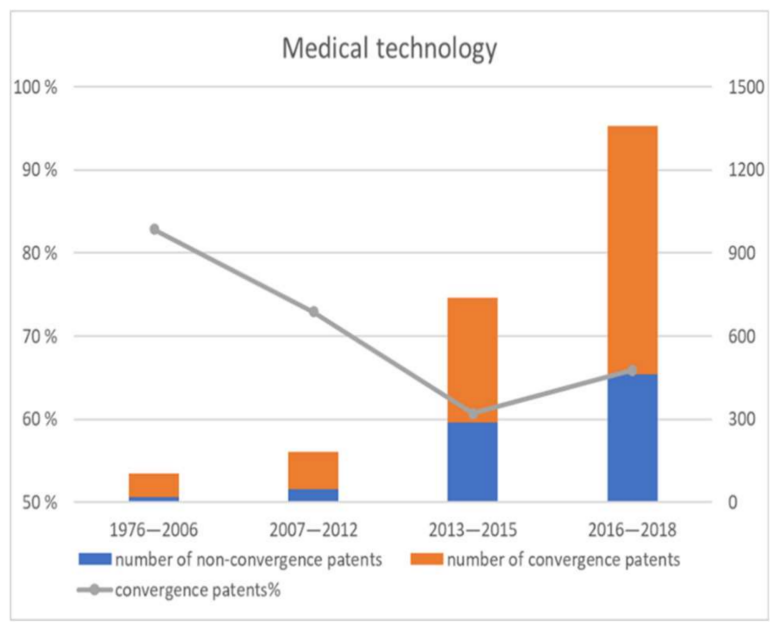

(d)

Figure 3. (a) Patent distribution and convergence trend in the field with the largest number of patents; (b) patent distribution and convergence trend in the field with the second largest number of patents;

(c) patent distribution and convergence trend in the field with the third largest number of patents; and

(d) patent distribution and convergence trend in the field with the fourth largest number of patents.

Analysis of the overall technology distribution of its patents and convergence show that, in recent years, with the rapid development of 3D printing technology, cross-domain convergence is becoming more and more generous. Therefore, the study of 3D printing technology convergence trends will assist innovators to have technology opportunities.

\subsection{Results of Reinforcing Technology Convergence}

In view of the large number of patents involved in this study and the need to meet the convergence measurement conditions, the FP-Growth algorithm was selected to mine association rules with a length of 2. By adjusting and testing the support threshold multiple times, the minimum support and minimum confidence were set to $3 \%$ and $50 \%$ respectively in this case. Twenty-seven association rules were generated in four periods, in which the number of rules in each period was 6, 6, 9 and 6 successively. Convergence measures are shown in Table 4, where count represents the number of patents that contain the corresponding association rule. A description of all IPC4 codes appearing in this article can be found in Appendix A Table A1.

First, half of the six association rules in the first period (1976-2006) were related to apparatus or arrangements for taking photographs or for projecting or viewing them (G03B), and all of them had high support, indicating that the focus of convergence in this period was G03B. In addition, technologies frequently integrated with G03B were optical elements, systems, or apparatus (G02B), pictorial communication $(\mathrm{H} 04 \mathrm{~N})$ and devices or arrangements related to light control (G02F). Considering the three key components of 3D printing technology, namely computer-aided design, molding equipment and materials, it can be found that the convergence generated around G03B was an area related to computer-aided design. This discovery is closely related to the early development of 3D printing technology, which is mainly stereolithography and digital light processing [61]. The confidence in rule 1 indicated that the technology involved in molding materials (B29K) also included shaping or joining of plastics (B29C), which is consistent with the upstream and downstream relationship between the two. The degree of convergence in this period was at a low level, among which the highest convergence degree was 0.360 for macromolecular compounds (C08F) and photomechanical production of textured or patterned surfaces $(\mathrm{G} 03 \mathrm{~F})$. 
In the second stage (2007-2012), G03B was still in the central position, but the devices or arrangements related to light control (G02F) in its related high-frequency convergence technology has been replaced by the arrangements or circuits for control of indicating devices using static means to present variable information (G09G), indicating that G09G has become an important direction of computer-aided design development. It is also worth noting that the high-frequency convergence of working metallic powder (B22F), additive manufacturing (B33Y) and shaping or joining of plastics (B29C) appeared in this period, which means that the industrial 3D printing technology has gradually developed. The result is mainly attributed to the expiration of FDM (Fused deposition modeling) patents, which improves the availability of technology. The pictorial communication (H04N) still acted a pivotal part in the integration process, and the average convergence degree has improved compared with that of the first stage.

The third stage (2013-2015) contained the largest number of rules, which were also significantly different from previous ones. G03B has been replaced by shaping or joining of plastics (B29C) and additive manufacturing (B33Y) as the leading convergence technology, which showed that the focus of 3D printing technology has shifted from early computer-aided design innovation to molding equipment innovation and manufacturing innovation. Soldering or unsoldering (B23K), shaping clay or other ceramic compositions (B28B), control or regulating systems in general (G05B), compounds consisting of inorganic or non-macromolecular organic substances (C08K) and compositions of macromolecular compounds $(\mathrm{C} 08 \mathrm{~L})$ at this stage were the prominent high-frequency convergence technologies, signifying that convergence concentration continues to expand into materials and manufacturing. The reflection in reality is the revolutionary application of $3 \mathrm{D}$ printing in biomedical, aerospace, architectural and protective structures, and the corresponding materials such as metal alloy, polymer composites, ceramics and concrete materials have made great progress [62]. In this period, the average convergence degree was lower than before, but some of them reached a medium level, as the Con dep between C08K and C08L was 0.591, which indicated that the longitudinal deepening of various convergences was significantly different.

Table 4. Association rules and degree of reinforcing technology convergence.

\begin{tabular}{|c|c|c|c|c|c|c|}
\hline Period & Id & Association Rules & Count & Support (\%) & Confidence (\%) & Con $_{\text {dep }}$ \\
\hline \multirow{6}{*}{ 1976-2006 } & 1 & $\mathrm{~B} 29 \mathrm{~K} \rightarrow \mathrm{B} 29 \mathrm{C}$ & 66 & $3.08 \%$ & $100.00 \%$ & 0.147 \\
\hline & 2 & G02B $\rightarrow$ G03B & 201 & $9.38 \%$ & $60.36 \%$ & 0.300 \\
\hline & 3 & $\mathrm{G} 02 \mathrm{~F} \rightarrow \mathrm{G} 03 \mathrm{~B}$ & 87 & $4.06 \%$ & $52.10 \%$ & 0.141 \\
\hline & 4 & $\mathrm{H} 04 \mathrm{~N} \rightarrow \mathrm{G} 03 \mathrm{~B}$ & 205 & $9.56 \%$ & $56.32 \%$ & 0.294 \\
\hline & 5 & $\mathrm{C} 08 \mathrm{~F} \rightarrow \mathrm{G03F}$ & 82 & $3.82 \%$ & $60.74 \%$ & 0.360 \\
\hline & 6 & G09G $\rightarrow \mathrm{H} 04 \mathrm{~N}$ & 101 & $4.71 \%$ & $54.01 \%$ & 0.224 \\
\hline \multirow{6}{*}{ 2007-2012 } & 7 & $\mathrm{~B} 22 \mathrm{~F} \rightarrow \mathrm{B} 29 \mathrm{C}$ & 97 & $4.29 \%$ & $53.30 \%$ & 0.158 \\
\hline & 8 & $\mathrm{~B} 33 \mathrm{Y} \rightarrow \mathrm{B} 29 \mathrm{C}$ & 183 & $8.10 \%$ & $86.73 \%$ & 0.329 \\
\hline & 9 & $\mathrm{G} 02 \mathrm{~B} \rightarrow \mathrm{G} 03 \mathrm{~B}$ & 186 & $8.23 \%$ & $63.92 \%$ & 0.292 \\
\hline & 10 & G09G $\rightarrow$ G03B & 87 & $3.85 \%$ & $50.88 \%$ & 0.141 \\
\hline & 11 & $\mathrm{H} 04 \mathrm{~N} \rightarrow \mathrm{G} 03 \mathrm{~B}$ & 243 & $10.75 \%$ & $58.70 \%$ & 0.346 \\
\hline & 12 & $\mathrm{G} 09 \mathrm{G} \rightarrow \mathrm{H} 04 \mathrm{~N}$ & 114 & $5.04 \%$ & $66.67 \%$ & 0.242 \\
\hline \multirow{9}{*}{ 2013-2015 } & 13 & $\mathrm{~B} 23 \mathrm{~K} \rightarrow \mathrm{B} 22 \mathrm{~F}$ & 360 & $3.22 \%$ & $74.53 \%$ & 0.157 \\
\hline & 14 & $\mathrm{~B} 22 \mathrm{~F} \rightarrow \mathrm{B} 29 \mathrm{C}$ & 1400 & $12.51 \%$ & $64.40 \%$ & 0.194 \\
\hline & 15 & $\mathrm{~B} 28 \mathrm{~B} \rightarrow \mathrm{B} 29 \mathrm{C}$ & 388 & $3.47 \%$ & $68.31 \%$ & 0.059 \\
\hline & 16 & $\mathrm{~B} 33 \mathrm{Y} \rightarrow \mathrm{B} 29 \mathrm{C}$ & 4150 & $37.08 \%$ & $83.60 \%$ & 0.572 \\
\hline & 17 & G05B $\rightarrow$ B29C & 350 & $3.13 \%$ & $79.19 \%$ & 0.054 \\
\hline & 18 & $\mathrm{~B} 22 \mathrm{~F} \rightarrow \mathrm{B} 33 \mathrm{Y}$ & 1357 & $12.12 \%$ & $62.42 \%$ & 0.235 \\
\hline & 19 & $\mathrm{~B} 23 \mathrm{~K} \rightarrow \mathrm{B} 33 \mathrm{Y}$ & 338 & $3.02 \%$ & $69.98 \%$ & 0.066 \\
\hline & 20 & $\mathrm{~B} 28 \mathrm{~B} \rightarrow \mathrm{B} 33 \mathrm{Y}$ & 368 & $3.29 \%$ & $64.79 \%$ & 0.071 \\
\hline & 21 & $\mathrm{C} 08 \mathrm{~K} \rightarrow \mathrm{C} 08 \mathrm{~L}$ & 420 & $3.75 \%$ & $83.17 \%$ & 0.591 \\
\hline \multirow{6}{*}{ 2015-2018 } & 22 & $\mathrm{~B} 22 \mathrm{~F} \rightarrow \mathrm{B} 33 \mathrm{Y}$ & 2695 & $14.45 \%$ & $89.27 \%$ & 0.197 \\
\hline & 23 & $\mathrm{~B} 28 \mathrm{~B} \rightarrow \mathrm{B} 33 \mathrm{Y}$ & 602 & $3.23 \%$ & $87.37 \%$ & 0.045 \\
\hline & 24 & $\mathrm{~B} 29 \mathrm{C} \rightarrow \mathrm{B} 33 \mathrm{Y}$ & 9258 & $49.63 \%$ & $93.89 \%$ & 0.664 \\
\hline & 25 & $\mathrm{C} 08 \mathrm{~K} \rightarrow \mathrm{B} 33 \mathrm{Y}$ & 766 & $4.11 \%$ & $82.99 \%$ & 0.057 \\
\hline & 26 & $\mathrm{C} 08 \mathrm{~L} \rightarrow \mathrm{B} 33 \mathrm{Y}$ & 892 & $4.78 \%$ & $79.64 \%$ & 0.066 \\
\hline & 27 & $\mathrm{C} 08 \mathrm{~K} \rightarrow \mathrm{C} 08 \mathrm{~L}$ & 842 & $4.51 \%$ & $91.22 \%$ & 0.701 \\
\hline
\end{tabular}


The convergence pattern in the fourth stage (2016-2018) was more concentrated than before, depending on the extension of additive manufacturing (B33Y), while the application areas were mainly focused on B29C, B22F, C08K, C08L and B28B, which were also the key areas of convergence in the third period. In addition, the support and confidence of B29C-B33Y were high, up to $49.63 \%$ and $93.89 \%$ respectively, indicating that the combination of shaping or joining of plastics (B29C) and additive manufacturing (B33Y) has become the mainstream of 3D printing technology. It is worth noting that compounds consisting of inorganic or non-macromolecular organic substances (C08K) and compositions of macromolecular compounds (C08L) not only started to frequently merge with additive manufacturing (B33Y), but the convergence degree between them was also increasing; it has reached 0.701, which has become the highest so far. Correspondingly, the average degree has significantly improved, but the specific differences in the degree of convergence were also obviously increased as well. The three-dimensional landscape of the development of association rules by period is shown in Figure 4. According to the figure, support was used as a measure of importance where the raised area represented the core convergence in each period. The higher the degree of protrusion is, the stronger its dominance will be.

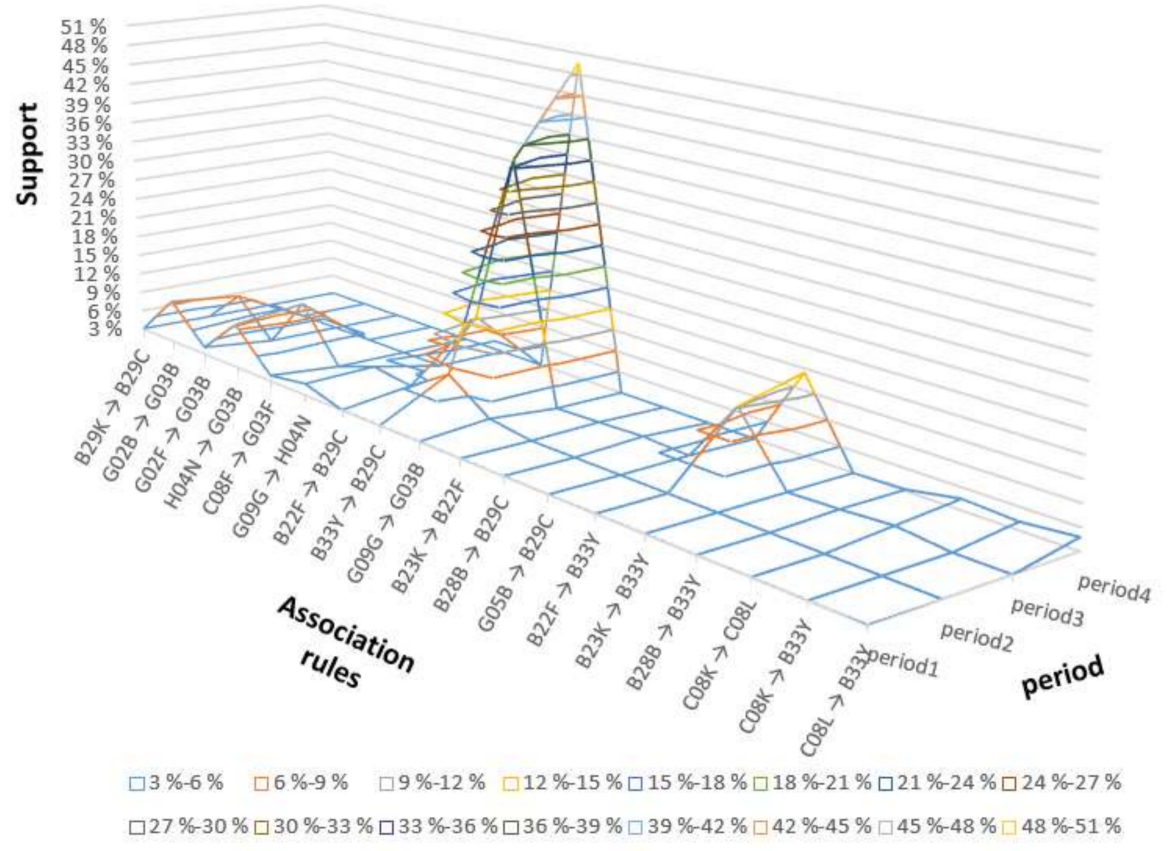

Figure 4. Landscape of reinforcing technology convergence development.

After studying the reinforcing technology convergence patterns based on association rules, information entropy has been further used to identify relevant core technology components. The technology components with the highest entropy in each stage are shown in Table 5. B33Y has always had a high entropy since the second period, and the rules related to it have increased, suggesting that B33Y has been an important component of 3D technology since 2007, and its core position has been continuously enhanced. In the latest period, B22F, C08L and B28B still had high entropies, as previously, which show their importance, while shaping or joining of plastics (B29C) showed high entropy in the first three periods, but with significantly reduction in the fourth period. Similarly, compounds consisting of inorganic or non-macromolecular organic substances (C08K) are no longer the center of gravity for recent 3D printing. The findings indicated that additive manufacturing (B33Y) was the dominant technology in the latest development of 3D printing, and B22F, C08L and B28B were the core technology fields. 
Table 5. IPC4 with the highest entropy by period.

\begin{tabular}{cccccccc}
\hline Period 1 & $\boldsymbol{E}_{\boldsymbol{i}}$ & Period 2 & $\boldsymbol{E}_{\boldsymbol{i}}$ & Period 3 & $\boldsymbol{E}_{\boldsymbol{i}}$ & Period 4 & $\boldsymbol{E}_{\boldsymbol{i}}$ \\
\hline G03F & 5.423 & B29C & 4.193 & B33Y & 3.064 & B33Y & 2.308 \\
C08F & 5.272 & G03B & 3.123 & B29C & 2.816 & B22F & 1.529 \\
B29C & 5.231 & H04N & 2.435 & B22F & 1.913 & C08L & 1.516 \\
G03B & 2.861 & B33Y & 2.211 & C08L & 1.907 & B28B & 1.223 \\
G02F & 2.433 & G09G & 2.137 & C08K & 1.276 & B29C & 0.896 \\
H04N & 2.216 & G02B & 1.921 & B28B & 1.252 & C08K & 0.838 \\
\hline
\end{tabular}

\subsection{Results of Novel Technology Convergence}

Novel technology convergence of 3D printing has been studied in this section. Finding out the emerging trends of novel technology convergence is also important for technology anticipation and forecasting. The development of novel technology convergence has been identified for four periods. Since new integration of technologies occurs in relation to existing ones, it has started from the second period. Table 6 shows the proportion of new convergence in the last three periods and their subsequent development. Columns titled "period $i$ " list the top 10 novel convergence relationships, i.e., IPC co-occurrence for the first time in period $i$, while columns "period $i$ to period $j$ " give the 10 most frequent co-occurrence relationships in period $j$ who appeared for the first time in period $i$. For period 2, B33Y and B29K appeared together in 1.73\% patents, and they were the most frequent new co-occurrence relations. Co-occurrence of additive manufacturing (B33Y) and control or regulating systems in general (G05B) happened in period 2 for the first time, and the relationship appeared in $2.47 \%$ patents in period 3. It is worth noting that the proportion of novel convergence in each period decreased, and the intensity of subsequent development was also greatly weakened, which denotes that the recent development of 3D printing presents the Matthew effect.

Table 6. The top 10 novel technology convergence in each of the subsequent periods.

\begin{tabular}{|c|c|c|c|c|c|c|}
\hline Id & Period 2 & $\begin{array}{c}\text { Period } 2 \text { to } \\
\text { Period } 3\end{array}$ & $\begin{array}{l}\text { Period } 2 \text { to } \\
\text { Period } 4\end{array}$ & Period 3 & $\begin{array}{l}\text { Period } 3 \text { to } \\
\text { Period } 4\end{array}$ & Period 4 \\
\hline 1 & $\begin{array}{c}\text { B33Y-B29K } \\
(1.73 \%)\end{array}$ & $\begin{array}{c}\text { B33Y-G05B } \\
(2.47 \%)\end{array}$ & $\begin{array}{c}\text { B33Y-A61L } \\
(1.31 \%)\end{array}$ & $\begin{array}{c}\text { B29C-B25J } \\
(0.26 \%)\end{array}$ & $\begin{array}{c}\text { B33Y-C12M } \\
(0.21 \%)\end{array}$ & $\begin{array}{c}\text { B33Y-E02D } \\
(0.05 \%)\end{array}$ \\
\hline 2 & $\begin{array}{c}\text { B29C-H04N } \\
(0.88 \%)\end{array}$ & $\begin{array}{c}\text { B33Y-B29K } \\
(2.08 \%)\end{array}$ & $\begin{array}{c}\text { B33Y-A61F } \\
(1.01 \%)\end{array}$ & $\begin{array}{c}\text { B33Y-C12M } \\
(0.26 \%)\end{array}$ & $\begin{array}{c}\text { B33Y-F16F } \\
(0.21 \%)\end{array}$ & $\begin{array}{c}\text { B33Y-G07F } \\
(0.04 \%)\end{array}$ \\
\hline 3 & $\begin{array}{c}\text { B22F-F01D } \\
(0.84 \%)\end{array}$ & $\begin{array}{c}\text { B33Y-G06T } \\
(1.22 \%)\end{array}$ & $\begin{array}{c}\text { B33Y-G06T } \\
(1.00 \%)\end{array}$ & $\begin{array}{c}\text { B33Y-H05B } \\
(0.22 \%)\end{array}$ & $\begin{array}{c}\text { B33Y-G09B } \\
(0.18 \%)\end{array}$ & $\begin{array}{c}\text { A43B-G06T } \\
(0.04 \%)\end{array}$ \\
\hline 4 & $\begin{array}{c}\text { B33Y-G05B } \\
(0.80 \%)\end{array}$ & $\begin{array}{c}\text { B33Y-C08J } \\
(0.80 \%)\end{array}$ & $\begin{array}{c}\text { B33Y-C08F } \\
(0.98 \%)\end{array}$ & $\begin{array}{c}\text { B22F-B08B } \\
(0.22 \%)\end{array}$ & $\begin{array}{c}\text { C08L-C08B } \\
(0.13 \%)\end{array}$ & $\begin{array}{c}\text { B33Y-G21C } \\
(0.04 \%)\end{array}$ \\
\hline 5 & $\begin{array}{c}\text { G06F-G06Q } \\
(0.75 \%)\end{array}$ & $\begin{array}{c}\text { B33Y-C08F } \\
(0.79 \%)\end{array}$ & $\begin{array}{c}\text { B33Y-C08J } \\
(0.86 \%)\end{array}$ & $\begin{array}{c}\text { B33Y-B25J } \\
(0.22 \%)\end{array}$ & $\begin{array}{c}\text { B33Y-H01F } \\
(0.12 \%)\end{array}$ & $\begin{array}{c}\text { B22F-G21C } \\
(0.04 \%)\end{array}$ \\
\hline 6 & $\begin{array}{c}\text { B33Y-A61F } \\
(0.58 \%)\end{array}$ & $\begin{array}{c}\text { B22F-F01D } \\
(0.72 \%)\end{array}$ & $\begin{array}{c}\text { B33Y-G05B } \\
(0.85 \%)\end{array}$ & $\begin{array}{c}\text { B33Y-C12N } \\
(0.21 \%)\end{array}$ & $\begin{array}{c}\text { B33Y-H05B } \\
(0.12 \%)\end{array}$ & $\begin{array}{c}\text { B29C-A61H } \\
(0.04 \%)\end{array}$ \\
\hline 7 & $\begin{array}{c}\text { B23P-F01D } \\
(0.58 \%)\end{array}$ & $\begin{array}{c}\text { B33Y-C08G } \\
(0.67 \%)\end{array}$ & $\begin{array}{c}\text { B33Y-B29K } \\
(0.77 \%)\end{array}$ & $\begin{array}{c}\text { B23P-F28F } \\
(0.21 \%)\end{array}$ & $\begin{array}{c}\text { B33Y-C08B } \\
(0.12 \%)\end{array}$ & $\begin{array}{c}\text { G06T-A43D } \\
(0.03 \%)\end{array}$ \\
\hline 8 & $\begin{array}{c}\text { B33Y-C08F } \\
(0.49 \%)\end{array}$ & $\begin{array}{c}\text { B33Y-B29B } \\
(0.67 \%)\end{array}$ & $\begin{array}{c}\text { B33Y-B29B } \\
(0.76 \%)\end{array}$ & $\begin{array}{c}\text { B33Y-B23Q } \\
(0.20 \%)\end{array}$ & $\begin{array}{c}\text { B33Y-B25J } \\
(0.11 \%)\end{array}$ & $\begin{array}{c}\text { B33Y-D03D } \\
(0.03 \%)\end{array}$ \\
\hline 9 & $\begin{array}{c}\text { B33Y-C08G } \\
(0.49 \%)\end{array}$ & $\begin{array}{c}\text { B33Y-A61F } \\
(0.64 \%)\end{array}$ & $\begin{array}{c}\text { B33Y-C08G } \\
(0.70 \%)\end{array}$ & $\begin{array}{c}\text { B33Y-G09B } \\
(0.16 \%)\end{array}$ & $\begin{array}{c}\text { B33Y-H01S } \\
(0.11 \%)\end{array}$ & $\begin{array}{c}\text { B33Y-F41H } \\
(0.03 \%)\end{array}$ \\
\hline 10 & $\begin{array}{c}\text { B23K-F01D } \\
(0.44 \%)\end{array}$ & $\begin{array}{c}\text { B33Y-A61L } \\
(0.63 \%)\end{array}$ & $\begin{array}{c}\text { B33Y-B01D } \\
(0.45 \%)\end{array}$ & $\begin{array}{c}\text { B28B-F01D } \\
(0.15 \%)\end{array}$ & $\begin{array}{c}\text { B22F-B08B } \\
(0.11 \%)\end{array}$ & $\begin{array}{c}\text { A61L-C09C } \\
(0.03 \%)\end{array}$ \\
\hline
\end{tabular}

Due to the low frequency of novel convergence in the early stage, cluster analysis based on the IPC co-occurrence network was utilized to reveal the novel convergence patterns in each period. In order to concentrate on more important convergence relationships, links with a frequency less than 4 were removed from the co-occurrence network. The community detection algorithm was used to identify 
the main communities of new convergence by period with the social network analysis software Gephi. The results of community division showed that there were a large number of small-scale communities in the co-occurrence network of each stage, and the community ranking fifth in size had a proportion of less than $10 \%$ of its members. Therefore, the communities ranking the top four in each stage were selected for detailed analysis. The relevant basic information is shown in Table 7, and a description of the IPC3 (3-digit IPC codes) involved in the table can be found in Appendix A Table A2.

Table 7. The top 4 communities of novel technology convergence networks.

\begin{tabular}{|c|c|c|c|}
\hline Period & Community & $\begin{array}{l}\text { Number of IPC4 } \\
\text { Included }\end{array}$ & Description \\
\hline \multirow{4}{*}{ 2007-2012 } & Community $1(33.33 \%)$ & 21 & $\begin{array}{l}\text { Centered on B33Y and involving } 11 \text { 3-bit IPC } \\
\text { classes which is mainly A61, B29, C08, F16 and } \\
\text { several subclasses of G section in IPC. }\end{array}$ \\
\hline & Community $2(22.22 \%)$ & 14 & $\begin{array}{c}\text { Centered on B29C and involving } 12 \text { 3-bit IPC } \\
\text { classes which is mainly A43, B29, C08, D01, F02, } \\
\text { G03, H04 and so on. }\end{array}$ \\
\hline & Community 3 (19.05\%) & 12 & $\begin{array}{l}\text { Centered on F01D and involving } 10 \text { 3-bit IPC } \\
\text { classes which is mainly B22, C22 and several } \\
\text { subclasses of F section in IPC. }\end{array}$ \\
\hline & Community $4(12.70 \%)$ & 8 & $\begin{array}{l}\text { Centered on G06F and G06Q and involving } 3 \\
\text { 3-bit IPC classes which is B44, G06 and H04. }\end{array}$ \\
\hline \multirow{5}{*}{ 2013-2015 } & Community $1(30.20 \%)$ & 45 & $\begin{array}{l}\text { Centered on B33Y and involving 24 3-bit IPC } \\
\text { classes which is mainly C12, F16, G01, H01 and } \\
\text { several subclasses of A and B sections in IPC. }\end{array}$ \\
\hline & & & Centered on B23K and B29L and involving 17 \\
\hline & Community $2(15.44 \%)$ & 23 & $\begin{array}{l}\text { 3-bit IPC classes which is mainly B23, F28, H01 } \\
\text { and several subclasses of C and E sections in IPC. } \\
\text { Centered on B22F and involving } 14 \text { 3-bit IPC }\end{array}$ \\
\hline & Community $3(13.42 \%)$ & 20 & $\begin{array}{l}\text { classes which is mainly B24, B64, F16 and several } \\
\text { subclasses of E, G and H sections in IPC. }\end{array}$ \\
\hline & Community $4(12.75 \%)$ & 19 & $\begin{array}{l}\text { Centered on B28B and involving } 16 \text { 3-bit IPC } \\
\text { classes which is mainly A61, B28 and several } \\
\text { subclasses of C, F, G and H sections in IPC. }\end{array}$ \\
\hline \multirow{4}{*}{ 2016-2018 } & Community $1(28.21 \%)$ & 11 & $\begin{array}{l}\text { Centered on B33Y and involving } 10 \text { 3-bit IPC } \\
\text { classes which is mainly B28, C08, D03, E02 and } \\
\text { several subclasses of F and G sections in IPC. }\end{array}$ \\
\hline & Community $2(15.38 \%)$ & 6 & $\begin{array}{l}\text { Centered on A43B and involving 4 3-bit IPC } \\
\text { classes which is A43, A61, C08 and G06. }\end{array}$ \\
\hline & Community 3 (15.38\%) & 6 & $\begin{array}{l}\text { Centered on B29C and involving } 63 \text {-bit IPC } \\
\text { classes which is A42, A61, B29, B60, F01 and F03. }\end{array}$ \\
\hline & Community $4(12.82 \%)$ & 5 & $\begin{array}{l}\text { Centered on C01F and involving } 5 \text { 3-bit IPC } \\
\text { classes which is A61, B01, C01, C08 and C09. }\end{array}$ \\
\hline
\end{tabular}

For the period 2007-2012, 63 IPC4 and 86 co-occurrence relationships were identified, and the network modularity was 0.566 . The results are visualized in Figure 5, where IPC4 with the same color indicates belonging to the same community. Among them, the community centered on additive manufacturing (B33Y) became the largest one, which contained one-third nodes in the overall network, and most of the other nodes were directly combined with additive manufacturing (B33Y), including medical or veterinary science, hygiene (A61), working of plastics (B29), organic macromolecular compounds (C08), thermal insulation in general (F16) and so on. The community centered on shaping or joining of plastics (B29C) came in second place, which mainly connected with footwear (A43), working of plastics (B29) and organic macromolecular compounds (C08). In addition, there were communities centered on non-positive-displacement machines or engines (F01D), electric digital data processing $(\mathrm{G} 06 \mathrm{~F})$ and data processing systems or methods (G06Q) connected with subclasses of B, F, and $\mathrm{H}$ sections in IPC respectively. 


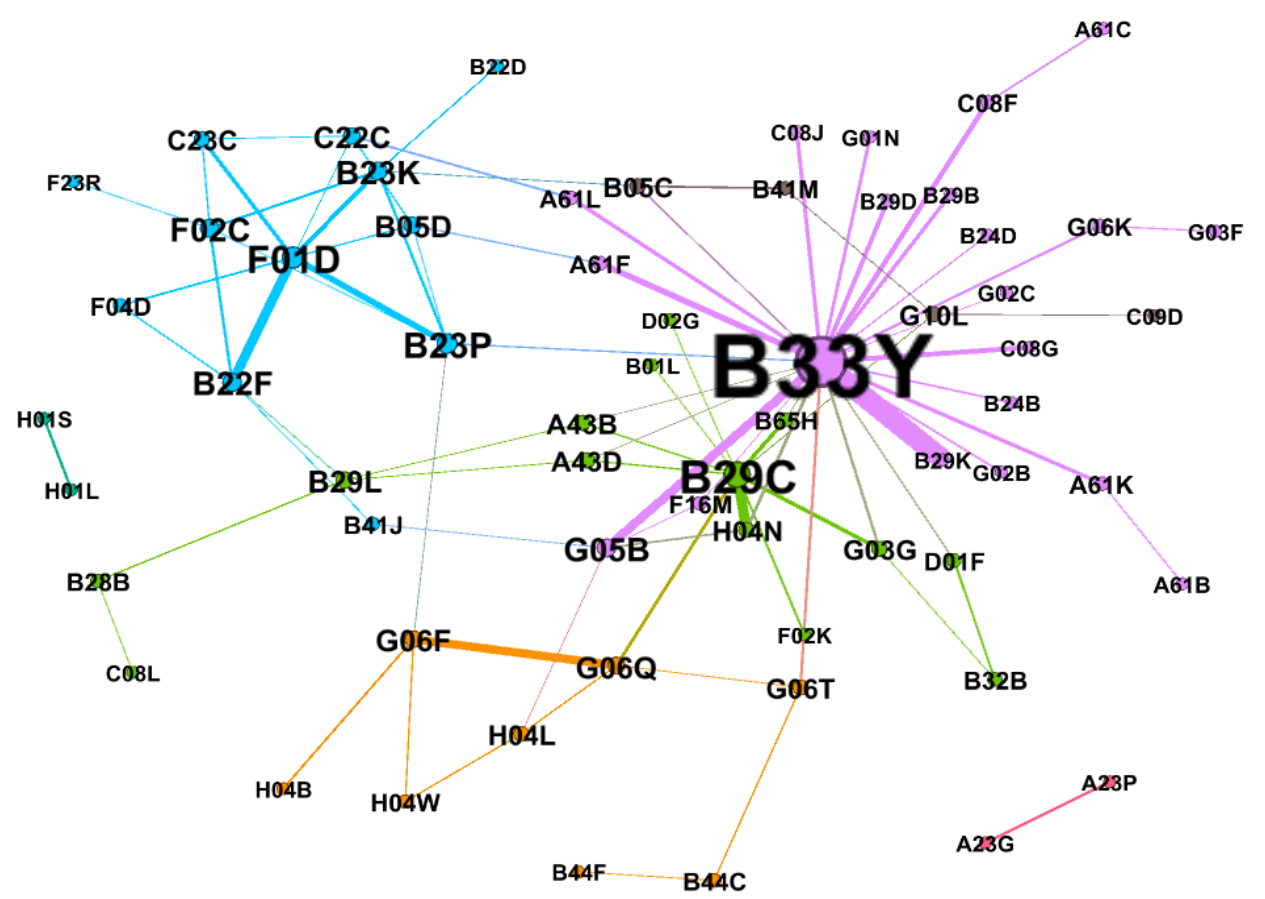

Figure 5. Co-occurrence network of new IPC4 combinations in period 2 (2007-2012).

During the period 2013-2015, the novel technology convergence was further expanded to 149 IPC4 and 230 co-occurrence relationships, as shown in Figure 6. The modularity of the network community was 0.491 . The most significant convergence in the identified communities was the connection of additive manufacturing (B33Y) with basic electric elements (H01), measuring or testing (G01), engineering elements or units (F16), biochemistry (C12), etc. Soldering or unsoldering (B23K), working metallic powder (B22F) and shaping clay or other ceramic compositions (B28B) were the convergence centers in this period. Apart from that, the technology fields related to building (E04F, E04G), machines or auxiliary tools for construction or repair (E01C), and earth or rock drilling (E21B) first appeared in $3 \mathrm{D}$ printing in period 3.

For the period 2016-2018, there were 39 IPC4 and 35 co-occurrence relationships identified, and it showed that the convergence patterns were more centralized than previously. Meanwhile, the network had the highest modularity of 0.637 . Figure 7 shows the visualization of its community divisions. It can be seen that additive manufacturing (B33Y) remained the core field of convergence, which was associated with shaping clay or other ceramic compositions (B28B), derivatives of natural macromolecular compounds (C08H), woven fabrics, methods of weaving or looms (D03D), dredging or soil-shifting (E02F) and some other fields. Characteristic features of footwear or parts of footwear (A43B) dominated the second largest community and related to organic macromolecular compounds (C08K, C08L) and image data processing or generation (G06T). Furthermore, A43B linked to electro therapy or magneto therapy $(\mathrm{A} 61 \mathrm{~N})$ and machines, tools, equipment or methods for manufacturing or repairing footwear (A43D) through G06T and C08L. Shaping or joining of plastics (B29C) and compounds of related metals or of the rare-earth metals $(\mathrm{C} 01 \mathrm{~F})$ played important roles in the convergence at this period as well. 


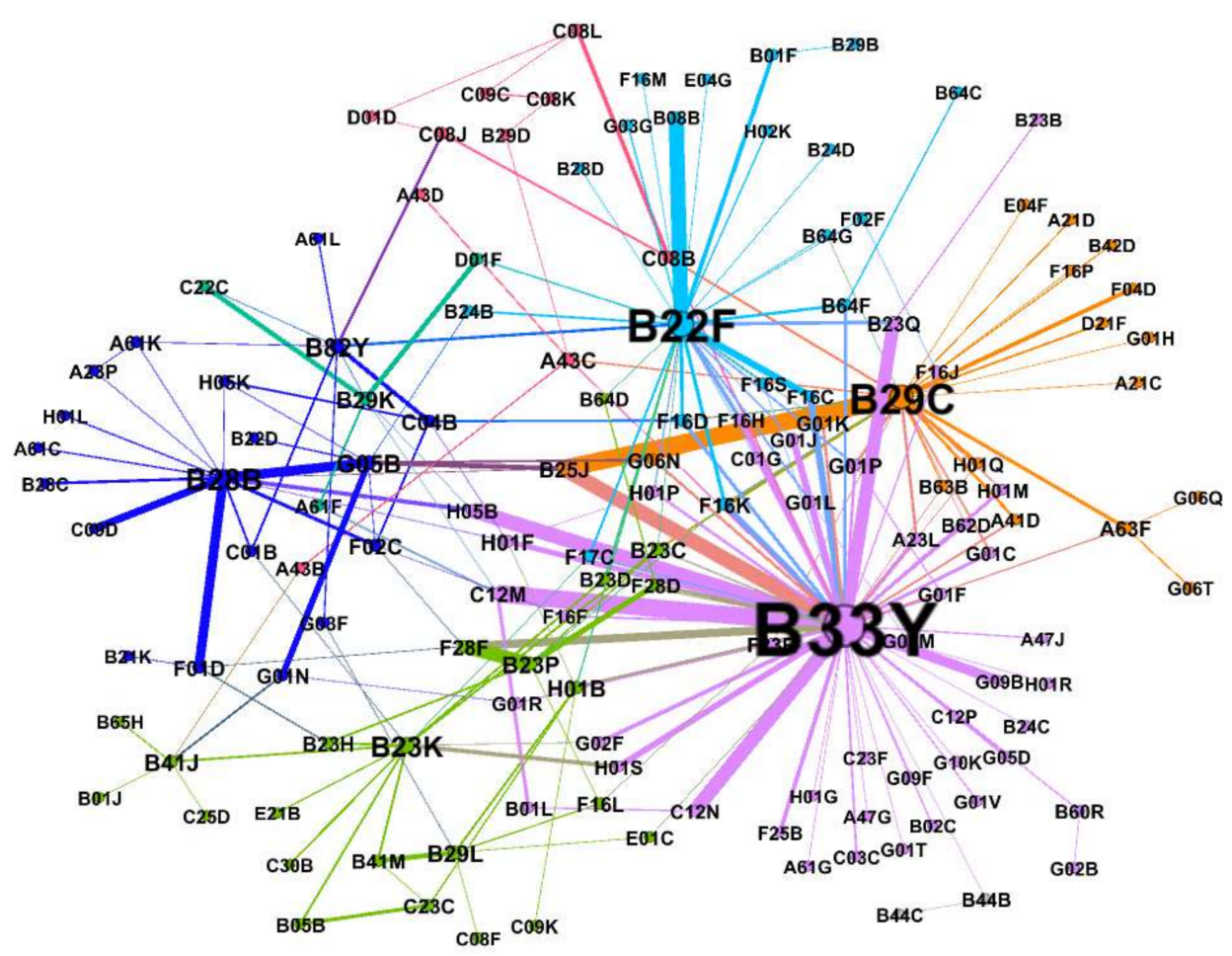

Figure 6. Co-occurrence network of new IPC4 combinations in period 3 (2013-2015).

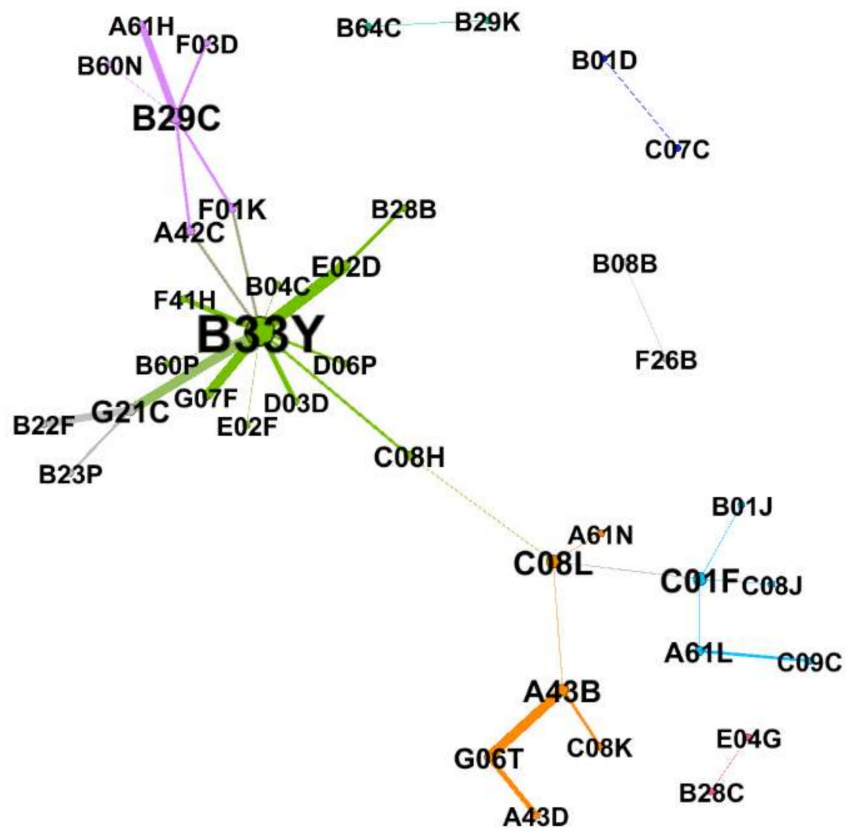

Figure 7. Co-occurrence network of new IPC4 combinations in period 4 (2016-2018).

In order to identify the core technology components in novel technology convergence, we calculated the betweenness centrality and bridging centrality of IPC4 involved in convergence by period. The former measures the importance of technology components in the core and overall development of IPC co-occurrence network, while the latter estimates the significance of technology components connecting local extension groups in IPC co-occurrence networks. Since most of the related IPC4 were located on the periphery of novel convergence, IPC4 ranked in the top ten of either betweenness 
centrality or bridging centrality were selected for core technology component identification. They are depicted in Figure 8, and all of them have been divided into four quadrants based on the averages of the two indicators accordingly. The implications of IPC codes in each quadrant are summarized in Table 8.
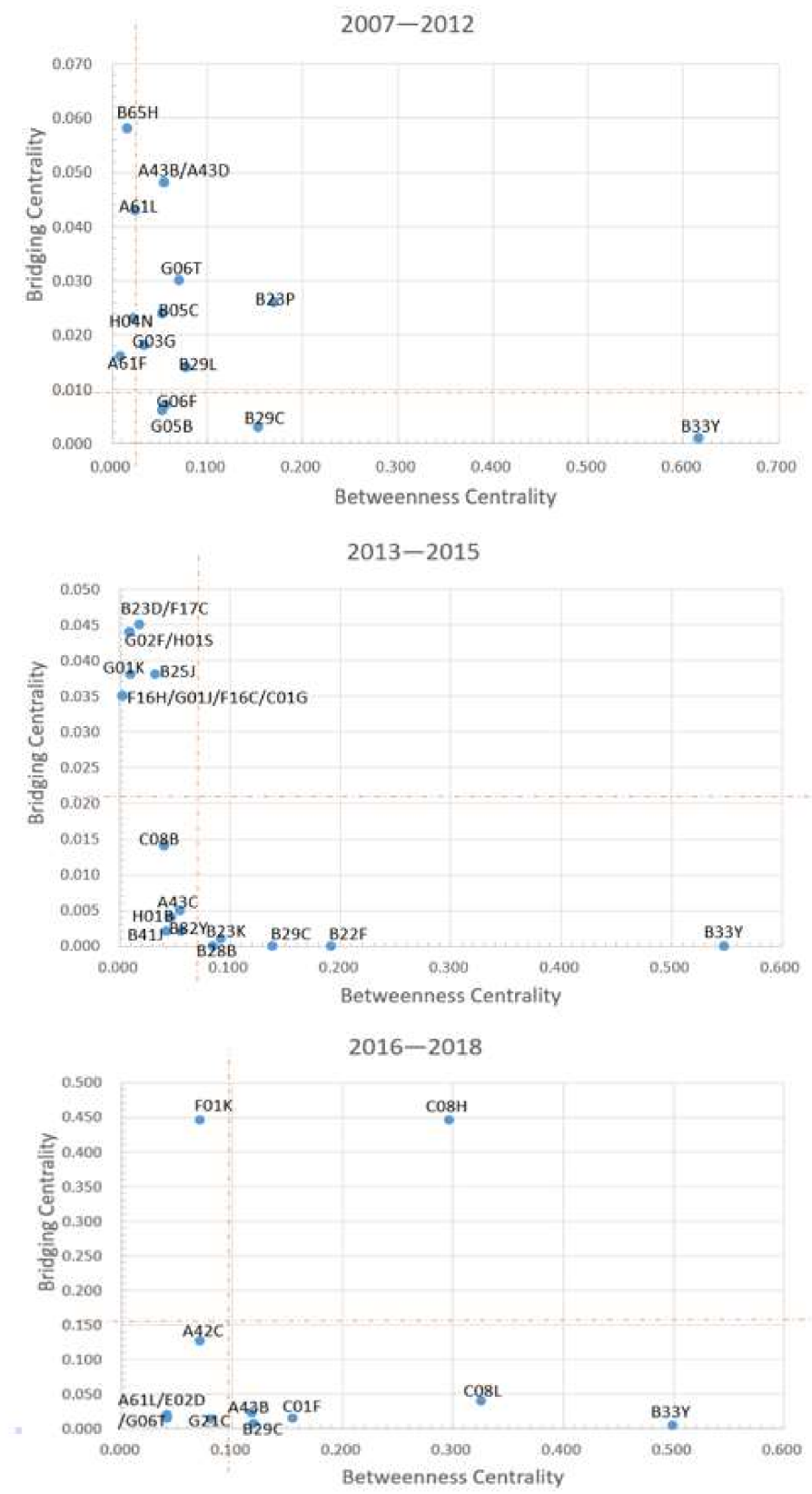

Figure 8. Betweenness centrality and bridging centrality of novel convergence networks.

In period 2 (2007-2012), the betweenness centrality of additive manufacturing (B33Y) and B29C ranked high, implying that they played important roles in the overall development of novel convergence. $\mathrm{B} 65 \mathrm{H}, \mathrm{A} 43 \mathrm{~B}, \mathrm{~A} 43 \mathrm{D}, \mathrm{A} 61 \mathrm{~L}$ and G06T had relatively high bridging centrality, which means they had great influence on the extension of local convergence. In addition, it should be noted that other working of metal, combined operations or universal machine tools (B23P) held high betweenness centrality and bridging centrality at the same time, and it was also one of the core technology components. When it comes to innovation in related domains, more attention needs to be paid. In period 3 (2013-2015), B33Y, B22F, B29C, B23K and B28B with high betweenness centrality were in the center of novel convergence, while B23D, F17C, G02F, H01S and some other technology fields with high 
bridging centrality controlled local knowledge flow. In period 4 (2016-2018), additive manufacturing (B33Y), compositions of macromolecular compounds (C08L), derivatives of natural macromolecular compounds $(\mathrm{C} 08 \mathrm{H})$ and compounds of related metals or of the rare-earth metals $(\mathrm{C} 01 \mathrm{~F})$ played leading roles in the development of convergence, while manufacturing or trimming hats or other head coverings (A42C), steam engine plants, steam accumulators, engine plants not otherwise provided for or engines using special working fluids or cycles (F01K) and derivatives of natural macromolecular compounds $(\mathrm{C} 08 \mathrm{H})$ mainly influenced the external extension. Here, the derivatives of natural macromolecular compounds $(\mathrm{C} 08 \mathrm{H})$ need to be especially emphasized, which is becoming a key technology component in novel convergence of 3D printing technology.

Table 8. The implications of IPC codes in each quadrant.

\begin{tabular}{cc}
\hline Quadrants & Implications \\
\hline First quadrant & $\begin{array}{c}\text { IPC codes have a high betweenness centrality and a high bridging centrality } \\
\text { These IPC codes play a vital role in the center of convergence and are closely } \\
\text { related to the local extensions of convergence }\end{array}$ \\
Second quadrant & $\begin{array}{r}\text { IPC codes have a low betweenness centrality and a high bridging centrality } \\
\text { These IPC codes are key technologies for local convergence extensions, but not } \\
\text { the whole. }\end{array}$ \\
Third quadrant & IPC codes have a low betweenness centrality and a low bridging centrality \\
Fourth quadrant & These IPC codes have a relatively low impact on technology convergence \\
IPC codes have a high betweenness centrality and a low bridging centrality \\
These IPC codes are closely related to the central development of convergence, \\
but not external extensions
\end{tabular}

Compared with the novel technology convergence and reinforcing technology convergence in each period, the former has been on the periphery of the development of 3D printing. Among them, the most significant growth was the combination of B33Y-G05B that appeared for the first time in the second period. It accounted for $2.47 \%$ of patents in the third period, but then its marginalization continued to increase. The reason may be that $3 \mathrm{D}$ printing research is in the early stages of a long evolution that, despite the confidence and enthusiasm for forecasting, has generally taken decades longer than expected to converge [7]. On the other hand, the reinforcing technology convergence changes over time, and it was in an expanding state in the third period, while the latest phase showed a highly characteristic concentration with different development priorities. This result is also affected by data truncation in the latest period. Given the overall technology convergence development of 3D printing, it is clear that it is evolving into a more complex and heterogeneous form [63], but the core trends of future development are also becoming clearer.

\section{Conclusions}

Technology convergence has increasingly become a mainstream phenomenon. It provides an exact path for innovation by acquiring new technologies through the convergence of different technologies. With the blurring of technology boundaries, breakthrough technology is more likely to occur between several different technology fields [33]. Learning about important convergence patterns and key components that can help organizations optimize resource allocation and promote sustainable development of the economy. Based on this, we proposed a comprehensive methodology to study technology convergence patterns. First, we selected the target field and collected relevant patent data, and then we divided the data into four groups according to the development process of the field. Secondly, we referred to the definition of technology convergence by Caviggioli [9] to carry out research from the perspective of reinforcing technology convergence and novel technology convergence respectively. The former used association rules to investigate the reinforcing patterns by period and measured the relevant convergence relationships, and then it identified the corresponding core technology components based on the information entropy. The latter examined the novel technology 
convergence patterns through community detection based on IPC co-occurrence network, and it identified the core technology components that affected the connection in each period according to betweenness centrality and the bridging centrality.

A result of reinforcing technology convergence shows that the 3D printing technology has gone through the convergence centered on apparatus or arrangements for taking photographs or for projecting or viewing them (G03B), optical elements, systems, or apparatus (G02B), pictorial communication $(\mathrm{H} 04 \mathrm{~N})$, etc., and changed to the convergence centered on shaping or joining of plastics (B29C), additive manufacturing (B33Y), working metallic powder (B22F), compositions of macromolecular compounds (C08L), etc., with the latter convergence patterns appearing as an enhanced trend. The convergence degree of different patterns varied greatly in each stage, among which B29C $\rightarrow \mathrm{B} 33 \mathrm{Y}$ and $\mathrm{C} 08 \mathrm{~K} \rightarrow \mathrm{C} 08 \mathrm{~L}$ reached the highest in history in the recent period. In terms of related core convergence components, the core position of B33Y has been continuously strengthened since it became a key component in the second stage (2007-2012). On the contrary, the influence of B29C, which played an important role in the first three stages, has been reduced in the latest stage and replaced by B22F, C08L and shaping clay or other ceramic compositions (B28B). As can be seen, the focus of the convergence development of 3D printing technology in recent years continues to expand to the fields of molding equipment, manufacturing process and materials.

The result of novel technology convergence shows that B33Y has been at the center of horizontal expansion of convergence for a long time, while the previous B29C and B22F are replaced by the later $\mathrm{C} 08 \mathrm{~L}$ and derivatives of natural macromolecular compounds $(\mathrm{C} 08 \mathrm{H})$. However, in general, the novel convergence patterns are marginalized, which is probably because 3D printing is still in the early stages of development, and it takes longer for the newly generated convergence to gain dominant power.

Compared with the existing technology convergence research, this study mainly makes the following contributions. On the one hand, the emerging periphery convergence patterns have been taken into account at the same time with the core convergence patterns. By investigating the development of novel technology convergence and identifying core technology components, it is beneficial to keep abreast of the development trend of relevant technology fields and seize the possible opportunities for breakthrough development. On the other hand, the study put forward effective methods with wider applicability to carry out convergence pattern research. Based on the form of association rules selected in this study, an appropriate measure index for convergence degree was elaborated on, while considering the weak development of novel convergence, the core technology components in convergence patterns were identified by using relevant network indicators.

However, there are some limitations of this study. Firstly, the IPC4 were selected in this study to carry out technology convergence research; therefore, relevant information cannot be fully utilized. Further research can consider more detailed IPC classes. Secondly, this study selected the association rule of two item-sets to carry out the research on reinforcing technology convergence patterns, ignoring the combination of multiple technology fields, which can be expanded on in the future. Then, the IPC4 combination in the proportion of patents in each period was used to represent the development of novel technology convergence, and a follow-up study can consider a more detailed tracking based on patent citation analysis. Finally, this study mainly focused on data mining, which did not extend the theory enough, and further research based on evolutionary theory can be carried out in the future.

Author Contributions: Conceptualization, X.L. and Z.C.; Formal analysis, Y.T.; Investigation, Y.T.; Methodology, Z.C.; Software, C.Z.; Visualization, Y.T. and C.Z.; Writing—original draft, Y.T.; Writing—review \& editing, X.L. and Z.C. All authors have read and agreed to the published version of the manuscript.

Funding: This work was supported by Grant-in-aid for scientific research from the National Natural Science Foundation for the Youth of China (No.71804147), Shaanxi Social Science Foundation of China (No.2017S037), Shaanxi department of education humanities and social sciences special research project of China (No.18JK0696), Special project of education department of Shaanxi province of China (No. 19JK0790), General program of humanities and social sciences of Shaanxi provincial ministry of education of China (No. 20YJA790033) and (No. 20YJC630010).

Conflicts of Interest: The authors declare that they have no conflicts of interest. 
Appendix A

Table A1. Description of the 4-digit IPC codes (IPC4) involved in the study.

\begin{tabular}{|c|c|c|c|}
\hline IPC4 & Description & IPC4 & Description \\
\hline $\mathrm{A} 42 \mathrm{C}$ & $\begin{array}{l}\text { Manufacturing or trimming hats or } \\
\text { other head coverings }\end{array}$ & C09C & $\begin{array}{l}\text { Treatment of inorganic materials, } \\
\text { other than fibrous fillers, to enhance } \\
\text { their pigmenting or filling properties }\end{array}$ \\
\hline A43B & $\begin{array}{l}\text { Characteristic features of footwear; } \\
\text { parts of footwear }\end{array}$ & $\mathrm{C} 12 \mathrm{M}$ & $\begin{array}{l}\text { Apparatus for enzymology or } \\
\text { microbiology }\end{array}$ \\
\hline $\mathrm{A} 43 \mathrm{C}$ & $\begin{array}{l}\text { Fastenings or attachments for } \\
\text { footwear; laces in general }\end{array}$ & $\mathrm{C} 12 \mathrm{~N}$ & $\begin{array}{l}\text { Microorganisms or enzymes; } \\
\text { compositions thereof }\end{array}$ \\
\hline A43D & $\begin{array}{l}\text { Machines, tools, equipment or } \\
\text { methods for manufacturing or } \\
\text { repairing footwear }\end{array}$ & D03D & $\begin{array}{l}\text { Woven fabrics; methods of weaving; } \\
\text { looms }\end{array}$ \\
\hline $\mathrm{A} 61 \mathrm{~F}$ & $\begin{array}{l}\text { Filters implantable into blood vessels; } \\
\text { prostheses; devices providing patency } \\
\text { to, or preventing collapsing of, } \\
\text { tubular structures of the body }\end{array}$ & E02D & $\begin{array}{l}\text { Foundations; excavations; } \\
\text { embankments; underground or } \\
\text { underwater structures }\end{array}$ \\
\hline $\mathrm{A} 61 \mathrm{H}$ & Physical therapy apparatus & F01D & $\begin{array}{c}\text { Non-positive-displacement machines } \\
\text { or engines }\end{array}$ \\
\hline $\mathrm{A} 61 \mathrm{~L}$ & $\begin{array}{l}\text { Methods or apparatus for sterilizing } \\
\text { materials or objects in general }\end{array}$ & F01K & $\begin{array}{l}\text { Steam engine plants; steam } \\
\text { accumulators; engine plants not } \\
\text { otherwise provided for }\end{array}$ \\
\hline B01D & Separation & F16C & $\begin{array}{l}\text { Shafts; flexible shafts; mechanical } \\
\text { means for transmitting movement in a } \\
\text { flexible sheathing }\end{array}$ \\
\hline B05C & $\begin{array}{l}\text { Apparatus for applying liquids or } \\
\text { other fluent materials to surfaces }\end{array}$ & $\mathrm{F} 16 \mathrm{~F}$ & $\begin{array}{l}\text { Springs; shock-absorbers; means for } \\
\text { damping vibration }\end{array}$ \\
\hline B08B & $\begin{array}{l}\text { Cleaning in general; prevention of } \\
\text { fouling in general }\end{array}$ & $\mathrm{F} 16 \mathrm{H}$ & Gearing \\
\hline $\mathrm{B} 22 \mathrm{~F}$ & $\begin{array}{l}\text { Working metallic powder; } \\
\text { manufacture of articles from metallic } \\
\text { powder; apparatus or devices } \\
\text { specially adapted for metallic powder }\end{array}$ & F17C & $\begin{array}{l}\text { Vessels for containing or storing } \\
\text { compressed, liquefied, or solidified } \\
\text { gases; fixed-capacity gas-holders; } \\
\text { filling vessels with, or discharging } \\
\text { from vessels, compressed, or } \\
\text { Solidified gases }\end{array}$ \\
\hline B23D & $\begin{array}{l}\text { Planning; slotting; shearing; } \\
\text { broaching; sawing; filing; scraping; } \\
\text { like operations for working metal by } \\
\text { removing material, not otherwise } \\
\text { provided for }\end{array}$ & $\mathrm{F} 28 \mathrm{~F}$ & $\begin{array}{l}\text { Details of heat-exchange or } \\
\text { heat-transfer apparatus, of } \\
\text { general application }\end{array}$ \\
\hline $\mathrm{B} 23 \mathrm{~K}$ & $\begin{array}{c}\text { Soldering or unsoldering; welding; } \\
\text { cladding or plating by soldering or } \\
\text { welding; cutting by applying } \\
\text { heat locally }\end{array}$ & $\mathrm{F} 41 \mathrm{H}$ & $\begin{array}{l}\text { Armor; armored turrets; armored or } \\
\text { armed vehicles; means of attack } \\
\text { or defense }\end{array}$ \\
\hline B23P & $\begin{array}{l}\text { Other working of metal; combined } \\
\text { operations; universal machine tools }\end{array}$ & G01J & $\begin{array}{l}\text { Measurement of intensity, velocity, } \\
\text { spectral content, polarization, phase } \\
\text { or pulse characteristics of infra-red, } \\
\text { visible or ultra-violet light; } \\
\text { colorimetry; radiation pyrometry }\end{array}$ \\
\hline $\mathrm{B} 23 \mathrm{Q}$ & $\begin{array}{l}\text { Details, components, or accessories } \\
\text { for machine tools }\end{array}$ & G01K & $\begin{array}{l}\text { Measuring temperature; measuring } \\
\text { quantity of heat; thermally-sensitive } \\
\text { elements not otherwise provided for }\end{array}$ \\
\hline B25J & $\begin{array}{l}\text { Manipulators; chambers provided } \\
\text { with manipulation devices }\end{array}$ & G02B & $\begin{array}{c}\text { Optical elements, systems, } \\
\text { or apparatus }\end{array}$ \\
\hline B28B & $\begin{array}{l}\text { Shaping clay or other ceramic } \\
\text { compositions, slag or mixtures } \\
\text { containing cementitious material, } \\
\text { e.g., plaster }\end{array}$ & $\mathrm{G} 02 \mathrm{~F}$ & $\begin{array}{l}\text { Devices or arrangements, the optical } \\
\text { operation of which is modified by } \\
\text { changing the optical properties of the } \\
\text { medium of the devices or } \\
\text { arrangements for the control of the } \\
\text { intensity, color, phase, Polarization or } \\
\text { direction of light }\end{array}$ \\
\hline
\end{tabular}


Table A1. Cont.

\begin{tabular}{|c|c|c|c|}
\hline IPC4 & Description & IPC4 & Description \\
\hline B29B & $\begin{array}{l}\text { Preparation or pretreatment of the } \\
\text { material to be shaped; making } \\
\text { granules or preforms; recovery of } \\
\text { plastics or other constituents of waste } \\
\text { material containing plastics }\end{array}$ & G03B & $\begin{array}{l}\text { Apparatus or arrangements for taking } \\
\text { photographs or for projecting or } \\
\text { viewing them; apparatus or } \\
\text { arrangements employing analogous } \\
\text { techniques using waves other than } \\
\text { optical waves; accessories therefor }\end{array}$ \\
\hline B29C & Shaping or joining of plastics & G03F & $\begin{array}{l}\text { Photomechanical production of } \\
\text { textured or patterned surfaces }\end{array}$ \\
\hline B29K & $\begin{array}{l}\text { Indexing scheme associated with } \\
\text { subclasses B29B, B29C or B29D, } \\
\text { relating to molding materials or to } \\
\text { materials for reinforcements, fillers or } \\
\text { preformed parts }\end{array}$ & G03G & $\begin{array}{l}\text { Electrography; electrophotography; } \\
\text { magnetography }\end{array}$ \\
\hline B29L & $\begin{array}{l}\text { Indexing scheme associated with } \\
\text { subclass B29C, relating to } \\
\text { particular articles }\end{array}$ & G05B & $\begin{array}{l}\text { Control or regulating systems in } \\
\text { general; functional elements of such } \\
\text { systems; monitoring or testing } \\
\text { arrangements for such systems or } \\
\text { elements }\end{array}$ \\
\hline B33Y & Additive manufacturing & G06F & Electric digital data processing \\
\hline B41J & $\begin{array}{c}\text { Typewriters; selective printing } \\
\text { mechanisms }\end{array}$ & G06Q & $\begin{array}{l}\text { Data processing systems or methods, } \\
\text { specially adapted for administrative, } \\
\text { commercial, financial, managerial, } \\
\text { supervisory or forecasting purposes }\end{array}$ \\
\hline $\mathrm{B} 65 \mathrm{H}$ & Handling thin or filamentary material & G06T & $\begin{array}{l}\text { image data processing or generation, } \\
\text { in general }\end{array}$ \\
\hline B82Y & $\begin{array}{c}\text { Specific uses or applications of } \\
\text { nanostructures; measurement or } \\
\text { analysis of nanostructures; } \\
\text { manufacture or treatment of } \\
\text { nanostructures }\end{array}$ & G07F & Coin-freed or like apparatus \\
\hline $\mathrm{C} 01 \mathrm{~F}$ & $\begin{array}{l}\text { Compounds of the metals beryllium, } \\
\text { magnesium, aluminum, calcium, } \\
\text { strontium, barium, radium, thorium, } \\
\text { or of the rare-earth metals }\end{array}$ & G09B & $\begin{array}{l}\text { Educational or demonstration } \\
\text { appliances; appliances for teaching, or } \\
\text { communicating with, the blind, deaf } \\
\text { or mute; models; planetaria; globes; } \\
\text { maps; diagrams }\end{array}$ \\
\hline C01G & $\begin{array}{l}\text { Compounds containing metals not } \\
\text { covered by subclasses C01D or C01F }\end{array}$ & G09G & $\begin{array}{l}\text { Arrangements or circuits for control } \\
\text { of indicating devices using static } \\
\text { means to present variable information }\end{array}$ \\
\hline C08B & Polysaccharides; derivatives thereof & G21C & Nuclear reactors \\
\hline $\mathrm{C} 08 \mathrm{~F}$ & $\begin{array}{l}\text { Macromolecular compounds obtained } \\
\text { by reactions only involving } \\
\text { carbon-to-carbon unsaturated bonds }\end{array}$ & H01B & $\begin{array}{l}\text { Cables; conductors; insulators; } \\
\text { selection of materials for their } \\
\text { conductive, insulating or } \\
\text { dielectric properties }\end{array}$ \\
\hline C08G & $\begin{array}{l}\text { Macromolecular compounds obtained } \\
\text { otherwise than by reactions only } \\
\text { involving carbon-to-carbon } \\
\text { unsaturated bonds }\end{array}$ & $\mathrm{H} 01 \mathrm{~F}$ & $\begin{array}{l}\text { Magnets; inductances; transformers; } \\
\text { selection of materials for their } \\
\text { magnetic properties }\end{array}$ \\
\hline $\mathrm{C} 08 \mathrm{H}$ & $\begin{array}{l}\text { Derivatives of natural } \\
\text { macromolecular compounds }\end{array}$ & H01S & $\begin{array}{l}\text { Devices using the process of light } \\
\text { amplification by stimulated emission } \\
\text { of radiation [laser] to amplify or } \\
\text { generate light }\end{array}$ \\
\hline C08J & $\begin{array}{l}\text { Working-up; general processes of } \\
\text { compounding }\end{array}$ & $\mathrm{H} 04 \mathrm{~N}$ & Pictorial communication \\
\hline C08K & $\begin{array}{c}\text { Use of inorganic or } \\
\text { non-macromolecular organic } \\
\text { substances as } \\
\text { compounding ingredients }\end{array}$ & H05B & $\begin{array}{l}\text { Electric heating; electric lighting not } \\
\text { otherwise provided for }\end{array}$ \\
\hline C08L & $\begin{array}{l}\text { Compositions of macromolecular } \\
\text { compounds }\end{array}$ & & \\
\hline
\end{tabular}

Source: adopted from International Patent Classification (version 2019) 
Table A2. Description of the 3-digit IPC codes (IPC3) involved in the study.

\begin{tabular}{|c|c|c|c|}
\hline IPC3 & Description & IPC3 & Description \\
\hline A42 & Headwear & $\mathrm{C} 12$ & $\begin{array}{l}\text { Biochemistry; beer; spirits; wine; } \\
\text { vinegar; microbiology; enzymology; } \\
\text { mutation or genetic engineering }\end{array}$ \\
\hline A43 & Footwear & $\mathrm{C} 22$ & $\begin{array}{l}\text { Metallurgy; ferrous or non-ferrous } \\
\text { alloys; treatment of alloys or } \\
\text { non-ferrous metals }\end{array}$ \\
\hline A61 & Medical or veterinary science; hygiene & D01 & $\begin{array}{c}\text { Natural or man-made threads or fibers; } \\
\text { spinning }\end{array}$ \\
\hline B01 & $\begin{array}{c}\text { Physical or chemical processes or } \\
\text { apparatus in general }\end{array}$ & D03 & Weaving \\
\hline B22 & Casting; powder metallurgy & E02 & $\begin{array}{l}\text { Hydraulic engineering; foundations; } \\
\text { soil-shifting }\end{array}$ \\
\hline B23 & $\begin{array}{l}\text { Machine tools; metal-working not } \\
\text { otherwise provided for }\end{array}$ & F01 & $\begin{array}{l}\text { Machines or engines in general; engine } \\
\text { plants in general; steam engines }\end{array}$ \\
\hline B24 & Grinding; polishing & F02 & $\begin{array}{l}\text { Combustion engines; hot-gas or } \\
\text { combustion-product engine plants }\end{array}$ \\
\hline B28 & Working cement, clay, or stone & F03 & $\begin{array}{l}\text { Machines or engines for liquids; wind, } \\
\text { spring, or weight motors }\end{array}$ \\
\hline B29 & $\begin{array}{l}\text { Working of plastics; working of } \\
\text { substances in a plastic state in general }\end{array}$ & F16 & $\begin{array}{l}\text { Engineering elements or units; general } \\
\text { measures for producing and } \\
\text { maintaining effective functioning of } \\
\text { machines or installations }\end{array}$ \\
\hline B44 & Decorative arts & F28 & Heat exchange in general \\
\hline $\mathrm{B} 60$ & Vehicles in general & G01 & Measuring; testing \\
\hline B64 & Aircraft; aviation; cosmonautics & G03 & $\begin{array}{l}\text { Photography; cinematography; } \\
\text { analogous techniques using waves } \\
\text { other than optical waves; electrography; } \\
\text { holography }\end{array}$ \\
\hline $\mathrm{C} 01$ & Inorganic chemistry & G06 & Computing; calculating; counting \\
\hline $\mathrm{C} 08$ & $\begin{array}{l}\text { Organic macromolecular compounds; } \\
\text { their preparation or chemical } \\
\text { working-up; compositions } \\
\text { based thereon }\end{array}$ & H01 & Basic electric elements \\
\hline $\mathrm{C} 09$ & $\begin{array}{c}\text { Dyes; paints; polishes; natural resins; } \\
\text { adhesives; compositions not } \\
\text { otherwise provided for }\end{array}$ & H04 & Electric communication technique \\
\hline
\end{tabular}

\section{References}

1. Adner, R. When are technologies disruptive? A demand-based view of the emergence of competition. Strat. Manag. J. 2002, 23, 667-688. [CrossRef]

2. Lei, D.T. Industry evolution and competence development: The imperatives of technological convergence. Int. J. Technol. Manag. 2000, 19, 699-738. [CrossRef]

3. Geum, Y.; Kim, C.; Lee, S.; Kim, M.S. Technological convergence of IT and BT: Evidence from patent analysis. ETRI J. 2012, 34, 439-449. [CrossRef]

4. Kim, M.S.; Kim, C. On a patent analysis method for technological convergence. Procedia Soc. Behav. Sci. 2012, 40, 657-663. [CrossRef]

5. Allarakhia, M.; Walsh, S. Analyzing and organizing nanotechnology development: Application of the institutional analysis development framework to nanotechnology consortia. Technovation 2012, 32, 216-226. [CrossRef]

6. Hacklin, F.; Raurich, V.; Marxt, C. How Incremental Innovation Becomes Disruptive: The Case of Technology Convergence. In Proceedings of the 2004 IEEE International Engineering Management Conference, Singapore, 18-21 October 2004; Volume 1, pp. 32-36.

7. Schnaars, S.; Thomas, G.; Irmak, C. Predicting the emergence of innovations from technological convergence: Lessons from the twentieth century. J. Macromarketing 2008, 28, 157-168. [CrossRef] 
8. Song, C.H.; Elvers, D.; Leker, J. Anticipation of converging technology areas-A refined approach for the identification of attractive fields of innovation. Technol. Forecast. Soc. Chang. 2017, 116, 98-115. [CrossRef]

9. Caviggioli, F. Technology fusion: Identification and analysis of the drivers of technology convergence using patent data. Technovation 2016, 55, 22-32. [CrossRef]

10. Chen, Y.; Tan, J.G.; Wang, Z.Q.; Liu, D.; Liu, Z.Y. Technological opportunity analysis of industrial robots from the perspective of patents. Sci. Res. Manag. 2018, 39, 144-156.

11. Kim, E.; Cho, Y.; Kim, W. Dynamic patterns of technological convergence in printed electronics technologies: Patent citation network. Scientometrics 2014, 98, 975-998. [CrossRef]

12. Lee, W.S.; Han, E.J.; Sohn, S.Y. Predicting the pattern of technology convergence using big-data technology on large-scale triadic patents. Technol. Forcast. Soc. Chang. 2015, 100, 317-329. [CrossRef]

13. Kim, J.; Kim, S.; Lee, C. Anticipating technological convergence: Link prediction using Wikipedia hyperlinks. Technovation 2019, 79, 25-34. [CrossRef]

14. Yasunaga, Y.; Watanabe, M.; Korenaga, M. Application of technology roadmaps to governmental innovation policy for promoting technology convergence. Technol. Forcast. Soc. Chang. 2009, 76, 61-79. [CrossRef]

15. Han, E.J.; Sohn, S.Y. Technological convergence in standards for information and communication technologies. Technol. Forcast. Soc. Chang. 2016, 106, 1-10. [CrossRef]

16. Alexander, L.; Van Knippenberg, D. Teams in pursuit of radical innovation: A goal orientation perspective. Acad. Manag. Rev. 2014, 39, 423-438. [CrossRef]

17. Christensen, C.M.; Raynor, M.E.; McDonald, R. What is disruptive innovation. Harv. Bus. Rev. 2015, 93, $44-53$.

18. Su, J.Q.; Liu, J.H.; Wang, Z.Q.; Chen, Y.; Jiang, Z.H. The evolution trajectory and early identification of disruptive technology by taking smartphones and other technologies as an example. Sci. Res. Manag. 2016, $37,13$.

19. Feng, K.; Zeng, D.M. Structural embeddedness of R\&D networks, concentration of technical standards, and technology convergence. Syst. Eng. 2018, 36, 5-16.

20. Rosenberg, N. Technological change in the machine tool industry, 1840-1910. J. Econ. Hist. 1963, 23, 414-443. [CrossRef]

21. Curran, C.S. The Anticipation of Converging Industries; Springer: London, UK, 2013.

22. Choi, J.; Jeong, S.; Kim, K. A study on diffusion pattern of technology convergence: Patent analysis for Korea. Sustainability 2015, 7, 11546-11569. [CrossRef]

23. Curran, C.S.; Leker, J. Patent indicators for monitoring convergence-Examples from NFF and ICT. Technol. Forcast. Soc. Chang. 2011, 78, 256-273. [CrossRef]

24. Nyström, A.G. What is Convergence? Perceptions from the Finnish Telecommunications Sector. In Proceedings of the 18th European Regional ITS Conference, Istanbul, Turkey, 2-4 September 2007.

25. Karvonen, M.; Kässi, T. Patent citations as a tool for analysing the early stages of convergence. Technol. Forcast. Soc. Chang. 2013, 80, 1094-1107. [CrossRef]

26. Kim, N.; Lee, H.; Kim, W.; Lee, H.; Suh, J.H. Dynamic patterns of industry convergence: Evidence from a large amount of unstructured data. Res. Policy 2015, 44, 1734-1748. [CrossRef]

27. Stieglitz, N. Digital dynamics and types of industry convergence: The evolution of the handheld computers market. Ind. Dyn. New Digit. Econ. 2003, 2, 179-208.

28. Kim, J.; Lee, S. Forecasting and identifying multi-technology convergence based on patent data: The case of IT and BT industries in 2020. Scientometrics 2017, 111, 47-65. [CrossRef]

29. Gauch, S.; Blind, K. Technological convergence and the absorptive capacity of standardisation. Technol. Forcast. Soc. Chang. 2015, 91, 236-249. [CrossRef]

30. Kim, D.H.; Lee, H.; Kwak, J. Standards as a driving force that influences emerging technological trajectories in the converging world of the Internet and things: An investigation of the M2M/IoT patent network. Res. Policy 2017, 46, 1234-1254. [CrossRef]

31. Jeong, S.; Lee, S. What drives technology convergence? Exploring the influence of technological and resource allocation contexts. J. Eng. Technol. Manag. 2015, 36, 78-96. [CrossRef]

32. Kose, T.; Sakata, I. Identifying technology convergence in the field of robotics research. Technol. Forcast. Soc. Chang. 2019, 146, 751-766. [CrossRef]

33. Jin, J.H.; Park, S.C.; Pyon, C.U. Finding research trend of convergence technology based on Korean R\&D network. Expert Syst. Appl. 2011, 38, 15159-15171. 
34. Hall, B.H.; Jaffe, A.B.; Trajtenberg, M. The NBER Patent Citation Data File: Lessons, Insights and Methodological Tools (No. w8498); National Bureau of Economic Research: Cambridge, MA, USA, 2001.

35. Ernst, H. Patent information for strategic technology management. World Pat. Inf. 2003, 25, $233-242$. [CrossRef]

36. Schmoch, U. Concept of a Technology Classification for Country Comparisons; Final Report to the World Intellectual Property Organisation; WIPO: Geneva, Switzerland, 2008.

37. Jaffe, A.B.; Trajtenberg, M.; Romer, P.M. Patents, Citations, and Innovations: A Window on the Knowledge Economy; The MIT Press: Cambridge, MA, USA, 2005.

38. Park, I.; Yoon, B. Technological opportunity discovery for technological convergence based on the prediction of technology knowledge flow in a citation network. J. Inf. 2018, 12, 1199-1222. [CrossRef]

39. Duysters, G.; Hagedoorn, J. Technological Convergence in the IT Industry: The Role of Strategic Technology Alliances and Technological Competencies. Int. J. Econ. Bus. 1998, 5, 355-368. [CrossRef]

40. Du, J.; Li, P.; Guo, Q.; Tang, X. Measuring the knowledge translation and convergence in pharmaceutical innovation by funding-science-technology-innovation linkages analysis. J. Inf. 2019, 13, 132-148. [CrossRef]

41. Xing, W.; Ye, X.; Kui, L. Measuring convergence of China's ICT industry: An input-output analysis. Telecommun. Policy 2011, 35, 301-313. [CrossRef]

42. Wang, F.; Pan, M.M. Industrial convergence, performance improvement and manufacturing industry growth: An empirical study based on panel data during 1998 to 2011. Stud. Sci. Sci. 2015, 33, 530-538.

43. Fai, F.; Von Tunzelmann, N. Industry-specific competencies and converging technological systems: Evidence from patents. Struct. Chang. Econ. Dyn. 2001, 12, 141-170. [CrossRef]

44. Shan, Y.Y.; Luo, W. An empirical study on the effect of industrial convergence on the optimization and upgrading of industrial structure-Taking the technology convergence of electronic information industry and manufacturing industry as an example. Enterp. Econ. 2013, 33, 49-56.

45. Li, Y.Y.; Zhao, Y.L. Method and application of technological convergence analysis base on patents. Stud. Sci. Sci. 2016, 34, 203-211.

46. Agrawal, R.; Srikant, R. Fast Algorithms for Mining Association Rules. In Proceedings of the 20th International Conference Very Large Data Bases (VLDB), Santiago, Chile, 12-15 September 1994; Volume 1215, pp. 487-499.

47. Aflori, C.; Craus, M. Grid implementation of the Apriori algorithm. Adv. Eng. Softw. 2007, 38, $295-300$. [CrossRef]

48. Borgelt, C. An Implementation of the FP-growth Algorithm. In Proceedings of the 1st International Workshop on Open Source Data Mining: Frequent Pattern Mining Implementations, Chicago, IL, USA, 21 August 2005; pp. 1-5.

49. Lancichinetti, A.; Fortunato, S. Community detection algorithms: A comparative analysis. Phys. Rev. E 2009, 80, 056117. [CrossRef] [PubMed]

50. Fortunato, S. Community detection in graphs. Phys. Rep. 2010, 486, 75-174. [CrossRef]

51. Newman, M.E. Modularity and community structure in networks. Proc. Natl. Acad. Sci. USA 2006, 103, 8577-8582. [CrossRef] [PubMed]

52. Blondel, V.D.; Guillaume, J.L.; Lambiotte, R.; Lefebvre, E. Fast unfolding of communities in large networks. J. Stat. Mech. Theory Exp. 2008, P10008. [CrossRef]

53. Brandes, U. A faster algorithm for betweenness centrality. J. Math. Sociol. 2001, 25, 163-177. [CrossRef]

54. Hwang, W.; Kim, T.; Ramanathan, M.; Zhang, A. Bridging Centrality: Graph Mining from Element Level to Group Level. In Proceedings of the 14th ACM SIGKDD International Conference on Knowledge Discovery and Data Mining, Las Vegas, NV, USA, 24-27 August 2008; pp. 336-344.

55. Ramanathan, M.; Zhang, A.; Cho, Y.R.; Hwang, W. Bridging centrality: Identifying bridging nodes in scale-free networks. Int. J. Adv. Netw. Appl. 2006, 9, 3669-3673.

56. Schubert, C.; Van Langeveld, M.C.; Donoso, L.A. Innovations in 3D printing: A 3D overview from optics to organs. Br. J. Ophthalmol. 2014, 98, 159-161. [CrossRef]

57. Koekoek, H.H. 3D Printing as an Emerging General Purpose Technology: Opportunities E Challenges; Eindhoven University of Technology: Eindhoven, The Netherlands, 2015.

58. Augustyn, J. Emerging Science and Technology Trends: 2016-2045 A Synthesis of Leading Forecasts; Future Scout: Los Angeles, CA, USA, 2016.

59. Liu, X.; Yu, X.; Zhang, B. China-US 3D Printing Patent Comparison Study and Implications for Chinese Industry Development. J. Intell. 2015, 5, 41-46. 
60. Wohlers, T.; Caffrey, T.; Campbell, R.I.; Diegel, O.; Kowen, J. Wohlers Report 2018: 3D Printing and Additive Manufacturing State of the Industry; Annual Worldwide Progress Report; Wohlers Associates: Fort Collins, CO, USA, 2018.

61. Ligon, S.C.; Liska, R.; Stampfl, J.; Gurr, M.; Mülhaupt, R. Polymers for 3D printing and customized additive manufacturing. Chem. Rev. 2017, 117, 10212-10290. [CrossRef]

62. Ngo, T.D.; Kashani, A.; Imbalzano, G.; Nguyen, K.T.; Hui, D. Additive manufacturing (3D printing): A review of materials, methods, applications and challenges. Compos. Part B Eng. 2018, 143, 172-196. [CrossRef]

63. Jeong, S.; Kim, J.C.; Choi, J.Y. Technology convergence: What developmental stage are we in? Scientometrics 2015, 104, 841-871. [CrossRef]

(C) 2020 by the authors. Licensee MDPI, Basel, Switzerland. This article is an open access article distributed under the terms and conditions of the Creative Commons Attribution (CC BY) license (http://creativecommons.org/licenses/by/4.0/). 